\title{
Turbulent kinetics of a large wind farm and their impact in the neutral boundary layer
}

\author{
Ji Sung $\mathrm{Na}$ \\ Department of Mechanical Engineering, Yonsei \\ University \\ Seoul, Republic of Korea \\ njs0712@yonsei.ac.kr \\ Domingo Muñoz-Esparza \\ Earth and Environmental Sciences, Los Alamos \\ National Laboratory \\ U.S.A. \\ dmunozes@lanl.gov

\section{Rodman Linn*} \\ Earth and Environmental Sciences, Los Alamos \\ National Laboratory \\ U.S.A. \\ $\underline{\text { rrl@lanl.gov }}$
}

\author{
Eunmo Koo \\ Earth and Environmental Sciences, Los Alamos \\ National Laboratory \\ U.S.A. \\ koo e@lanl.gov \\ Emilia Kyung Jin \\ Korea Institute of Atmospheric Prediction Systems \\ (KIAPS) \\ Seoul, Republic of Korea \\ k.jin@kiaps.org

\section{Joon Sang Lee*} \\ Department of Mechanical Engineering, Yonsei \\ University \\ Seoul, Republic of Korea \\ joonlee@yonsei.ac.kr
}




\section{ABSTRACT}

High-resolution large-eddy simulation of the flow over a large wind farm (64 wind turbines) is performed using the HIGRAD/FIRETEC-WindBlade model, which is a high-performance computing wind turbine-atmosphere interaction model that uses the Lagrangian actuator line method to represent rotating turbine blades. These high-resolution large-eddy simulation results are used to parameterize the thrust and power coefficients that contain information about turbine interference effects within the wind farm. Those coefficients are then incorporated into the Weather Research and Forecasting (WRF) model in order to evaluate interference effects in larger-scale models. In the high-resolution WindBlade wind farm simulation, insufficient distance between turbines creates the interference between turbines, including significant vertical variations in momentum and turbulent intensity. The characteristics of the wake are further investigated by analyzing the distribution of the vorticity and turbulent intensity. Quadrant analysis in the turbine and post-turbine areas reveals that the ejection motion induced by the presence of the wind turbines is dominant compared to that in the other quadrants, indicating that the sweep motion is increased at the location where strong wake recovery occurs. Regional-scale WRF simulations reveal that although the turbulent mixing induced by the wind farm is partly diffused to the upper region, there is no significant change in the boundary layer depth. The velocity deficit does not appear to be very sensitive to the local distribution of turbine coefficients. However, differences of about $5 \%$ on parameterized turbulent kinetic energy were found depending on the turbine coefficient distribution. Therefore, turbine coefficients that consider interference in the wind farm should be used in wind farm parameterization for largerscale models to better describe sub-grid scale turbulent processes.

Keywords:

1.Large wind farm 2.Actuator line method 3.Large-eddy simulation 4.Regional-scale simulation 5.Wind farm parameterization 6. Neutral boundary layer 


\section{INTRODUCTION}

Interest in harvesting wind energy has grown considerably in recent years due to attempts to reduce reliance on fossil fuels. In order to optimize the use of power transmission infrastructure, increase wind energy harvesting and manage installation and maintenance logistics and cost, wind turbines are grouped to form large wind farms or turbine arrays. Another significant change that has occurred over the last decade is the change in the size of wind turbines. Typical bladeswept areas have increased in diameter from $50 \mathrm{~m}$ or less to $100 \mathrm{~m}$ or more. This increase in the size of wind farms and turbines has strengthened their potential to cause their feedback in the surrounding atmosphere; this has inspired important research on the interaction between the local environment and wind farms [Petersen et al., 1998, Vermeer et al., 2003].

There have been many studies investigating the impact of wind farms on the weather and climate using numerical models [Roy et al., 2004, Kirk-Davidoff and Keith, 2008]. Both regional and global models have been used to focus on the atmospheric responses on various spatial and temporal scales. How to represent the effect of wind farms in numerical models is one of the key issues in these studies. To use a proper variable is important because it can become a main parameter to describe the turbulent kinetic mechanism of wind farms.

Global circulation models (GCM) have been used to investigate how wind farms affect the climate. The effect of a wind farm has been represented as increased surface roughness in a GCM due to its coarse grid resolution. Previous studies that have used a GCM with increased surface roughness have reported that offshore wind farms can decrease the local sea surface temperature by enhancing latent heat and changing cloud formation and local precipitation [Keith et al., 2004, Wang and Prinn 2010, 2011]. However, it is difficult to determine the mechanism of interaction between the local environment and a wind farm using the increased surface roughness method, because the wake phenomena cannot be directly resolved due to its geometrical limitation [Fitch et al., 2013].

An intermediate treatment, which represents the wind farm effect as a sink of kinetic energy associated with the mean flow kinetic energy (KE) and a producer of turbulent kinetic energy (TKE), has been used for meso-scale or regional-scale models such as weather research and forecasting (WRF) models or the regional atmospheric modeling system (RAMS). Such studies have suggested significant changes in surface temperatures and local precipitation in areas with wind farms [Adams and Keith, 2007, Roy and Traiteur, 2010, Fitch et al., 2012]. This approach 
assumes that the KE deficit caused by a wind farm can be equated to the electrical power generated by the wind farm and the TKE production is estimated through the power coefficient $\mathrm{C}_{\mathrm{P}}$, thrust coefficient $\mathrm{C}_{\mathrm{T}}$ and TKE coefficient $\mathrm{C}_{\mathrm{TKE}}$. However, although this method attempts to represent more aspects of the wind turbine effects on the surrounding atmosphere compared to simply increasing the surface roughness, it still has inherent limitations in its ability to resolve the impacts of wind farms with numerous turbines. For example, the ideal turbine coefficients used in this methodology, which are often provided by manufacturers, do not account for turbineto-turbine interactions or in-array wake turbulence. Therefore, they may not properly describe the characteristics of large-scale wind farms, which are different from the simple sum of individual turbines.

To investigate the interaction between the local environment and a wind farm, the atmospheric boundary layer (ABL) must be considered, because the ABL is influenced directly by the earth's surface [Stull, 1988, Na et al., 2014]. Thus, the KE deficit (i.e., the effects of downstream disturbances or wakes produced by a wind farm), which is characterized by vortical structures such as tip, helical and shear vortices, directly affects the velocity profile, convection and turbulence mixing in the ABL [Porté-Agel et al., 2011].

Research into the effects of wind farms on the neutral boundary layer (NBL), which exclude the effects of surface buoyancy fluxes and stratification, are less commonly investigated than effects on the convective boundary layer (CBL) and the stable boundary layer (SBL). SBL studies by Lu and Porté-Agel, and Park et al. reported that the KE deficit and the generation of the TKE induced by the wind farm affects the suppression of the nocturnal low-level jet and the development of the boundary layer [Lu and Porté-Agel, 2011, Park et al., 2014]. Also, CBL studies by Wei-Zhang et al. and Porté-Agel et al. reported that the turbine-enhanced turbulent mixing in the CBL may play a smaller role compared to the SBL because the boundary layer height in the CBL is larger [Wei-Zhang et al., 2013, Porté-Agel et al., 2014].

Since the KE deficit due to a wind farm wake is strongly related to the turbine coefficients, the process used to determine the proper coefficients for a wind farm is important. Furthermore, investigation of various kinetics of a wind farm is helpful for developing new parameterizations for wind farm dynamics. In order to obtain coefficients that capture the influence of turbine-toturbine interactions in a wind farm and to improve our ability to study various wind farm kinetics, we performed a high-resolution, large-eddy simulation of flow over a large wind farm. 
This was done using the HIGRAD/FIRETEC-WindBlade (hereafter referred to as WindBlade) model, which is a large eddy simulation model with the actuator line method approach to represent the effects of rotating individual turbine blades. Results from WindBlade calculations were synthesized into turbine coefficients (i.e. power and thrust coefficients) for each of the turbines within the wind farm. The coefficients were implemented in the wind farm parameterization of the WRF model in order to evaluate local environmental impact of the wind farm and its mechanisms in the NBL.

In Section 2, descriptions of the governing equations and numerical schemes of the two models and the initial and boundary condition sets are presented. In Section 3.1, the turbulent properties of the wind farm, turbine coefficients, and the kinetics of the wake are analyzed. Using both the coefficients obtained in Section 3.1 and the resulting parameterization of the wind farm influences, the impact of the wind farm in the NBL is evaluated in Section 3.2. Conclusions are presented in Section 4.

\section{NUMERICAL METHODS}

\subsubsection{Governing equations for wind farm simulation}

WindBlade was developed with the intention of simulating the two-way interaction between the atmosphere and wind turbines on a wind farm [Linn and Koo, 2011, Linn and Koo, 2012]. WindBlade was developed on the HIGRAD/FIRETEC model framework, which solves 3-D, time-dependent, compressible grid-filtered Navier-Stokes equations for velocity components and scalars with Coriolis and gravity forces [Linn, 1997, Pimont et al., 2009, Cunningham et al, 2013]. HIGRAD/FIRETEC is discretized using the finite volume approach and is second-order accurate in space and time. It uses a multidimensional positive definite advection transport algorithm (MPDATA) scheme [Smolarkiewicz and Margolin, 1998] to solve advection of variables and a conservative forward-in-time technique [Reisner et al., 2000]. Equations (1) through (3) are conservation equations for momentum, heat, and mass, respectively.

$$
\begin{aligned}
& \frac{\partial \rho u_{i}}{\partial t}+\frac{\partial \rho u_{i} u_{j}}{\partial x_{j}}=-\frac{\partial p}{\partial x_{j}}+\rho g_{i}-2 \varepsilon^{j k}{ }_{i} \omega_{j} u_{k}-\frac{\partial R_{i j}}{\partial x_{j}}-\rho C_{d} a_{v}|u| u_{i}+\alpha_{i}^{m}\left(\rho u_{i}-\rho u_{i}^{e}\right)+f \\
& \frac{\partial \rho \theta_{p}}{\partial t}+\frac{\partial \rho u_{j} \theta_{p}}{\partial x_{j}}=\sigma \frac{\partial^{2} \theta_{p}}{\partial x_{j}^{2}}+\alpha^{\theta}{ }_{i}\left(\rho \theta_{p}-\rho \theta_{p}{ }^{e}\right)
\end{aligned}
$$




$$
\frac{\partial \rho}{\partial t}+\frac{\partial \rho u_{j}}{\partial x_{j}}=0
$$

where $u_{i}$ is the Cartesian velocity component in the spatial direction $(x, y, z), g_{i}$ is the vector component of gravitational acceleration. The term, $2 \varepsilon^{j k}{ }_{i} \omega_{j} u_{k}$ represents the Coriolis force due to the Earth's rotation $\omega$ and $\varepsilon^{j k}{ }_{i}$ is the anti-symmetric tensor. $R_{i j}$ is the Reynolds stress tensor. $C_{d}$ is the vegetation drag coefficient and $a_{v}$ is the ratio between the surface area of the vegetation and the resolved grid volume. $f$ is the surface forcing by the blades of wind turbines. The potential temperature $\theta_{p}$ is defined as $\theta_{p}=T\left(P_{0} / P\right)^{R_{d} / C_{P}}$ where $P_{0}$ is a reference pressure set to $1,000 \mathrm{hPa}, T$ is the temperature, $R_{d}$ is the gas constant for dry air, and $C_{p}$ is the heat capacity at a constant pressure. $\sigma$ is the sub-grid scale (SGS) turbulent diffusion coefficient for heat. HIGRAD/FIRETEC uses a multi-scale approach with two specific length scales ( $s_{A}$ and $s_{B}$ corresponding to the half grid scale and the quarter grid scale, respectively) that are considered in the SGS scale. Also, the SGS TKE of each length scale are defined as $K_{A}$ and $K_{B}$. Based on the work of Shaw and Patton (2003) the SGS TKE can be split into multiple frequency bands where the sum of the SGS Reynolds stress at each scale is equal to the total SGS Reynolds stress.

$R_{i j}=R_{i j, A}+R_{i j, B}$ with $R_{i j, n}=\frac{2}{3} \delta_{i j} \rho\left(v_{t, n} \frac{\partial u_{k}}{\partial x_{k}}+K_{n}\right)-\rho v_{t, n}\left(\frac{\partial u_{i}}{\partial x_{j}}+\frac{\partial u_{j}}{\partial x_{i}}\right)$

where $n$ represents each length scale, $\mathrm{A}$ and $\mathrm{B}$, and $\delta_{i j}$ is the Kronecher delta function. According to the Prandtl-Kolmogorov approach (Pope, 2000), the SGS eddy viscosity coefficient at scale $\mathrm{n}, v_{t, n}$ is defined as follows

$v_{t, n}=0.09 \rho s_{n} K_{n}^{1 / 2}$

By obtaining the dot-product between Equation (1) and the Cartesian velocity, the SGS TKE balance equations are obtained at each scale. 


$$
\begin{aligned}
& \frac{\partial}{\partial t}\left(\rho K_{A}\right)+\frac{\partial}{\partial x_{j}}\left(\rho K_{A} u_{j}\right)=\frac{\partial}{\partial x_{j}}\left(\rho v_{t, A} \frac{\partial K_{A}}{\partial x_{j}}\right)+\frac{\partial u_{i}}{\partial x_{j}}\left[\rho v_{t, A}\left(\frac{\partial u_{i}}{\partial x_{j}}+\frac{\partial u_{j}}{\partial x_{i}}\right)-\frac{2}{3} \delta_{i j}\left(\rho v_{t, A} \frac{\partial u_{k}}{\partial x_{k}}+\rho K_{A}\right)\right] \\
& -\rho \frac{\sqrt{K_{A}+K_{B}}}{s_{A}} K_{A}-4 \rho C_{d} a_{v} K_{A}\left(u_{j} u_{i}\right)^{\frac{1}{2}} \\
& \frac{\partial}{\partial t}\left(\rho K_{B}\right)+\frac{\partial}{\partial x_{j}}\left(\rho K_{B} u_{j}\right)=\frac{\partial}{\partial x_{j}}\left(\rho v_{t, B} \frac{\partial K_{B}}{\partial x_{j}}\right)+\frac{\partial u_{i}}{\partial x_{j}}\left[\rho v_{t, B}\left(\frac{\partial u_{i}}{\partial x_{j}}+\frac{\partial u_{j}}{\partial x_{i}}\right)-\frac{2}{3} \delta_{i j}\left(\rho v_{t, B} \frac{\partial u_{k}}{\partial x_{k}}+\rho K_{B}\right)\right] \\
& -\rho \frac{\sqrt{K_{A}+K_{B}}}{s_{B}} K_{B}+4\left(K_{A}-K_{B}\right) \rho C_{d} a_{v}\left(u_{j} u_{i}\right)^{\frac{1}{2}}
\end{aligned}
$$

To represent the turbine blades and their interaction with the atmosphere in the HIGRAD/FIRETEC framework, wind turbines are modeled with WindBlade. WindBlade represents the aerodynamic turbine blade load, disturbance in the local atmospheric flows and thus turbine performance, turbine wakes and turbine-turbine interaction using a Lagrangian representation of the turbine in an Eulerian hydrodynamics grid. In WindBlade, aerodynamic forces caused by the wind turbine blade elements are calculated based on the local relative velocity field and the aerodynamic characteristics of the wind turbine blades (angle of attack, chord length, and lift and drag coefficients). The relative velocity is calculated by subtracting the local wind velocity from the velocity of the rotating blade, which is composed of the angular velocity of the blade and the radius of the blade in the $(r, \theta)$ plane, where $r$ and $\theta$ are the radial axis and angular axis, respectively: $V_{r e l}=\left(V_{r}, V_{\theta}-\Omega r\right)$. The angle of attack, $\alpha$, is obtained by subtracting the rotor angle, $\phi$, from the pitch angle, $\gamma$. The rotor angle is the angle between $V_{r e l}$ and the plane swept by the blade: $\phi=\tan ^{-1}\left(V_{r} / \Omega r-V_{\theta}\right)$. The forcing induced by the blade along its length is defined as follows:

$$
f=\frac{1}{2} V_{r e l}^{2} c\left(C_{L} e_{L}+C_{D} e_{D}\right)
$$

where $C_{L}$ and $C_{D}$ are the lift coefficient and drag coefficient, respectively. These coefficients are functions of the angle of attack and Reynolds number. Additionally $c$ is the chord length and $e_{L}$ and $e_{D}$ are the unit vectors in the direction of the lift and the drag, respectively. The angular velocity of the rotor, $\Omega$, is calculated based on the integration of the azimuthal forces along the length of each turbine blade, the moment of inertia of the wind turbine rotor, and the 
turbine generator control scheme. The control scheme used for this work is modeled after the National Renewable Energy Laboratory's (NREL) 5-MW reference turbine. Details about the turbine control scheme and turbine specification are available in Jonkman et al. (2009). The turbine blades were also modeled after the 5-MW NREL reference turbine. For example, the rated rotating speed of the rotor, the hub height, and the blade diameter were set to $12.1 \mathrm{rpm}, 90$ $\mathrm{m}$, and $126 \mathrm{~m}$, respectively. Sixty-four turbines were modeled, with a distance between turbines of about $430 \mathrm{~m}$; this corresponds to a spacing distance that is 3.4 times the turbine rotor diameter (3.4D).

\subsubsection{Case description for the high-resolution wind farm simulation}

The model domain for simulating the interaction between turbines in a wind farm spanned $6 \mathrm{~km}$ x $6 \mathrm{~km}$ x $0.8 \mathrm{~km}$ in the $x, y$, and $z$ directions, respectively. Additionally, 800 x 800 x 80 grid cells were used for the calculations. The grid is stretched vertically, but not horizontally: thus the horizontal grid resolution is $7.5 \mathrm{~m}$ and variable vertical resolution with $2.5 \mathrm{~m}$ at the surface to capture smaller-scale dynamics near the ground and turbines. The drag force caused by tall grass with a height of $0.7 \mathrm{~m}$ on the ground is modeled to represent the effects of surface roughness. A Dirichlet boundary condition using a constant vertical profile of wind speed that follows the $1 / 7^{\text {th }}$ law with $8 \mathrm{~m} \mathrm{~s}^{-1}$ as a reference velocity at the hub height was imposed. Winds are damped towards the prescribed ambient condition at the outlet. Free-shear boundary conditions were applied at the top boundary, using the Rayleigh damping layer that prevents rapid changes in the variables such as velocities and scalars. Damping was applied at heights above $600 \mathrm{~m}$. The total physical time for the wind farm simulation was $800 \mathrm{~s}$. Total number of processors used for calculation is 576, and wall clock time of calculation is 350,208 hours. Sixty-four 126-m diameter turbines were arranged in a square array with $3.4 \mathrm{D}$ downwind lateral spacing. To clearly observe the interference effect between turbines, a distance of 3.4D was chosen based on $2.5 \mathrm{D} \sim 4 \mathrm{D}$ distance where the pressure is fully recovered, according to the analytical study of Frandsen et al., (2006). A detailed simulation description is provided in Figure 1-(a).

\subsubsection{Thrust coefficient and power coefficient}

To parameterize the effects of each wind turbine in the wind farm, turbine coefficients (e.g. the thrust coefficient and power coefficient) were determined from the high-resolution HIGRAD- 
WindBlade wind farm simulation. To calculate these coefficients, a simple method based on the ratio of the upstream velocity, $V_{1}$, to the velocity near the rotor, $V_{2}$, is used. In order to cancel out local differences created by wake effects, these velocities are obtained based on spatial averaging in the vicinity of the rotor area. Spatial averaging is performed at the middle point between the stream-wise distribution of turbines and a distance of one grid cell behind the turbines, based on the assumption that the velocity at this middle point is the free-stream velocity.

$V_{1}=\iint_{\sqrt{y^{2}+z^{2} \leq D / 2}} u\left(x_{0}-1.7 D, y_{0}-y, z_{h}-z\right) d y d z$

$V_{2}=\iint_{\sqrt{y^{2}+z^{2}} \leq D / 2} u\left(x_{0}+7.5, y_{0}-y, z_{h}-z\right) d y d z$

$C_{T}=4 a(1-a), C_{p}=4 a(1-a)^{2}$.

where $x_{0}, y_{0}$ are the horizontal locations of turbines and $z_{h}$ is the hub height, and $a$ is the velocity ratio, $V_{2} / V_{1}$.

\subsubsection{Numerical model for regional-scale simulations}

For the present multi-scale study, the regional-scale numerical model WRF version 3.6 is used. The WRF model can be employed to simulate multi-scale flow from numerical weather prediction to the flow in the planetary boundary layer. The grid type used is Arakawa grid C. Cumulus processes, radiation and a microphysics processes are excluded, because we simulate the idealized NBL in the lower portion of the troposphere with a short convection time. The MYNN PBL scheme [Nakanishi, 2001], which is based on the Mellor-Yamada TKE scheme, is considered to account for the turbulent SGS processes in the atmospheric boundary layer. Also, surface layer processes are dealt with in the MYNN surface layer scheme. This WRF setup is chosen to be consistent with the LES wind farm simulation and to reduce the number of factors interacting with the boundary-layer and wind-turbine parameterization. A similar setup has been used in recent studies by Mirocha et al. (2014), Muñoz-Esparza et al. (2014) and Muñoz-Esparza et al. (2015) to understand meso-scale to LES transitions. The reason why we select the MYNN PBL scheme is that this PBL scheme includes a prognostic equation for SGS TKE as required by Fitch et al. (2012). 
To apply the effect of the wind farm in the WRF model, we used a wind farm parameterization that represents the wind farm as a sink of KE and a source of SGS TKE [Fitch et al., 2012] in the wind farm region:

$$
\begin{aligned}
& \frac{\partial|V|_{i j k}}{\partial t}=\frac{-\frac{1}{2} N_{i j}^{t} C_{T}|V|_{i j k}^{2} A_{i j k}}{\left(z_{k+1}-z_{k}\right)}, \\
& \frac{\partial u_{i j k}}{\partial t}=\frac{u_{i j k}}{|V|_{i j k}} \frac{\partial|V|_{i j k}}{\partial t}, \\
& \frac{\partial v_{i j k}}{\partial t}=\frac{v_{i j k}}{|V|_{i j k}} \frac{\partial|V|_{i j k}}{\partial t}, \\
& \frac{\partial T K E_{i j k}}{\partial x_{k}}=\frac{-\frac{1}{2} N_{i j}^{t}\left(C_{T}-C_{p}\right)|V|_{i j k}^{3} A_{i j k}}{\left(z_{k+1}-z_{k}\right)},
\end{aligned}
$$

where $N_{i j}^{t}$ is the number of turbines, $C_{T}$ is the thrust coefficient, $C_{p}$ is the power coefficient, and $A_{i j k}$ is the area swept by the turbine blade.

The amount of KE sink and SGS TKE source is mainly determined by thrust and power coefficients. Therefore, evaluation of coefficients with and without interference on the wind farm is performed in Section 3.2.

\subsubsection{Case description for regional-scale simulations}

The model domains used for the idealized regional-scale simulations consist of an outer domain for generating realistic mean atmospheric boundary layer inflow conditions and a nested domain where the wind farm effect is applied. To prevent atmospheric inflow from being affected by the wind farm, a one-way nesting approach was considered. The outer domain spanned $40.32 \mathrm{~km} \times$ $40.32 \mathrm{~km} \times 1 \mathrm{~km}$ in the $x, y$, and $z$ directions, respectively, with a grid comprised of $32 \times 32 \times$ 100 grid cells. The nested domain spanned $22.68 \mathrm{~km} \times 22.68 \mathrm{~km} \times 1 \mathrm{~km}$ in the $x, y$, and $z$ directions, respectively, with a grid comprised of $54 \times 54 \times 100$ grid cells. In the $x y$-directions, a periodic boundary condition is applied to the outer domain, while an interpolated boundary calculated from the coarse domain is applied in the nested domain. In the time integration, we set the time step to $1 \mathrm{~s}$ and $1 / 3 \mathrm{~s}$ for the outer and nest domains, respectively. 
The geostrophic wind was set to $10 \mathrm{~m} \mathrm{~s}^{-1}$ and $0 \mathrm{~m} \mathrm{~s}^{-1}$ in the $x$ and $y$ directions $\left(U_{g}\right.$ and $V_{g}$, respectively), and the strength of the initial temperature stratification was set at $0.003 \mathrm{~K} \mathrm{~m}^{-1}$ at a height of $400 \mathrm{~m}$, which was approximately the height of the initial inversion layer, while a uniform value of $300 \mathrm{~K}$ was used for the neutrally-stratified boundary layer. The surface roughness length was $0.1 \mathrm{~m}$. The intensity of the Rayleigh-damping layer was controlled by the Rayleigh-damping factor, which was set to 0.1 . Damping started weakly at $\mathrm{z}=800 \mathrm{~m}$ and increased according to the square of a sine function to its maximum value at the top boundary of the domain $(1,000 \mathrm{~m})$. The total physical time required to reach a quasi-steady state was $14 \mathrm{~h}$ $(50,400 \mathrm{~s})$. A detailed description of the simulation is provided in Figure 1-(b).

\section{RESULTS}

\subsection{Turbulent kinetics of the wind farm}

Figure 2-(a) illustrates the magnitude and distribution of the stream-wise velocity in the highresolution WindBlade simulation, where the velocity deficit induced by the wind farm is clearly shown. A stream-wise velocity deficit occurred behind the turbines, and the distribution of the deficit showed local variation along the columns due to interactions between turbines. Coherent structures and wake phenomena induced by the interactions were present in the velocity deficit region. These coherent structures are defined as shear vortices by the velocity deficit behind the turbine rotor. The wake behind the last row of turbines of the wind farm aligned in the streamwise direction was sustained for approximately 1,000 $\mathrm{m}(\sim 8 \mathrm{D})$. The high-speed velocity in the gaps between blades was observed behind the $1^{\text {st }}$ row of turbines at hub height. None of the turbine wakes, except those behind the last row, showed full recovery of momentum before the next row of turbines, because of the short distance between turbine rows.

As wakes accumulated in the stream-wise direction, their lateral extent grew due to entrainment and mixing. This caused interference between turbines in the span-wise direction. As shown in Figure 2-(b), the velocity deficits and wakes also varied in the vertical direction. After the third row ( $\sim 6.8 \mathrm{D}$ after the $1^{\text {st }}$ row), which is also where span-wise interactions started, the vertical extent of the coherent structures induced by the wind turbines began to grow. 
Figure 3-(a) shows the changes in the diffused coherent structure of individual turbine rows. In the $1^{\text {st }}$ row, the coherent structure, comprised mainly of tip vortices near the blade tip, was distributed in the area swept by the diameter of the blade $(126 \mathrm{~m})$. In the $2^{\text {nd }}$ row, the coherent structure was diffused in the radial direction of each turbine due to the fact that the wake in the $2^{\text {nd }}$ row was combined with the wake in the $1^{\text {st }}$ row, which was already mixed as it was advected 3.4D downstream. Figure 3-(a) shows that the span-wise interference between turbines in the same row is generated near the surface after the third row of turbines. It is clear that the interference between turbines was influenced by feedback from the developing boundary layer, which was driven by interaction near the surface. The shear gradient shown in Figure 3-(b) indicates that the patter of the turbine influence was largely radial except near the surface where mixing of the higher momentum downward air was constrained by the surface, enhancing lateral mixing.

Figure 4 illustrates the profiles of the mean stream-wise velocity averaged over the wind farm extent at different times ranging from $0 \mathrm{~s}$ to $800 \mathrm{~s}$. In the period between $600 \mathrm{~s}$ and $800 \mathrm{~s}$, the time variance of the velocity converged, indicating that the flow reached a quasi-steady state. To observe the time-averaged results, we obtained data at $10 \mathrm{~s}$ intervals during the above period. Furthermore, the difference between the velocity profiles at the final time and at the initial time indicated that the mean flow KE decreased in the area swept by the blades.

In Figure 5, profiles of the velocity deficit, recovery and TKE gain are plotted in the half area of the wind farm for the $1^{\text {st }}, 3^{\text {rd }}, 5^{\text {th }}, 7^{\text {th }}$ rows. A comparison of the left and right panels of Figure 5 reveals that the deficit in the KE was highly correlated with a gain in TKE for both the magnitude and peak location. In the $1^{\text {st }}$ row, there was some local variance in the span-wise direction. However it was observed that $5 \sim 6 \%$ of local variance occurred due to the strong wake. A decrease in the energy extraction caused by wake accumulation was observed in all of the velocity deficit plots, except for the $7^{\text {th }}$ row. The reason for the high velocity deficit in the $7^{\text {th }}$ row was that high velocity recovery occurred in the rear rows. This means that the velocity at the $7^{\text {th }}$ row decreased due to the presence of the turbines in the $8^{\text {th }}$ row, while only the velocity at the $8^{\text {th }}$ row recovered. 
The presence of wakes behind the wind turbines resulted in turbulent mixing, illustrated by the vorticity magnitude. Tip vortices and root vortices were identified by the iso-surface of the vorticity magnitude at two different times, $30 \mathrm{~s}$ and at $100 \mathrm{~s}$ after initiation of turbine operations. As shown in Figure 6-(a), at $\mathrm{t}=30 \mathrm{~s}$, tip vortices and root vortices were dominant. Vortices in all of the turbines had a similar shape, because there was almost no interaction between turbines until the wakes were advected 3.4D downstream to the downstream turbines, which did not occur until after $50 \mathrm{~s}$. In contrast, as time approached $100 \mathrm{~s}$, turbine wakes became more complex and contained additional types of vortices caused by turbine-to-turbine interactions and interactions between the developing resolved surface-shear-induced turbulence, which was not present at the inflow. A shear layer caused by the high speed in the gap between blades was also present. This high shear created shear vortices that caused wake diffusion in the radial direction at the interface of the shear layer.

To analyze the vertical distribution of the turbulence intensity, the root mean square of the velocity perturbations at each height normalized by the local mean stream-wise velocity is shown in Figure 7. Since the wakes were mainly composed of stream-wise velocity deficits and because these perturbations were larger in magnitude than the cross-stream or vertical entrainment velocities, the turbulence in the wake was not isotropic. Turbulent intensity in the stream-wise direction was about three times stronger than that in the span-wise and vertical directions. Production of stream-wise turbulence is partially due to the fact that, in this component of the velocity, the turbine blades cut perpendicular to the stream-wise velocity in the presence of vertical shear. This configuration results in asymmetrical mixing of faster winds into slower moving winds on one side of the turbine and slower moving air into faster moving air on the opposite side of the turbine. This mixing configuration results in a maximum turbulence value just below the rotor height where the blade motion in mostly vertical (in the direction of the shear) and the vertical wind shear is significant. This is consistent with the results observed by Linn et al. (2010) and Koo et al. (2011). The peak in the span-wise turbulent intensity near the surface is due to the mixing that occurs in the wake of the turbine tower. In this region, entrainment due to velocity fluctuations in the crosswind direction (xy-plane) is largely responsible for the recovery of the stream-wise velocity. 
To evaluate the effect of the wind farm on the turbulent characteristics of the boundary layer, we performed quadrant analysis of the Reynolds stress related to TKE production. Following the SBL study of Na et al. (2014), the horizontal velocity was defined and the $q^{\prime} w^{\prime}$ Reynolds stress was calculated $\left(q^{\prime}\right.$ is the horizontal velocity fluctuation and $w^{\prime}$ is the vertical velocity fluctuation). According to the sign of the two velocity fluctuations, the $q^{\prime} w^{\prime}$ Reynolds stress can be divided into four quadrants. The $1^{\text {st }}$ quadrant and $3^{\text {rd }}$ quadrant reflect turbulence dissipation, whereas the $2^{\text {nd }}$ quadrant (ejection motion) and $4^{\text {th }}$ quadrant (sweep motion) reflect turbulence production. Because fluctuations in the horizontal velocity and vertical velocity were considered, the sweep and ejection motions transporting the faster moving wind downward into the slower mean flow and the slower moving air traveling upward into the faster moving air were captured in quadrants 4 and 2, respectively. To observe how the wind farm affects the generation of vertical mixing, the simulation domain was divided into the turbine area and the post-turbine area. Vertical profiles of the four quadrants in the two areas are shown in Figure 8. The sum of the $2^{\text {nd }}$ and $4^{\text {th }}$ quadrants was comparable to that of the $1^{\text {st }}$ and $3^{\text {rd }}$ quadrants when the magnitude was vertically integrated over the whole height, indicating that TKE production and dissipation were balanced. In the turbine area, the ejection motion was about six to seven times stronger than the sweep motion based on the vertically averaged value at every height and at the area swept by the rotor, respectively. The radially diffused wake had a tendency for upward turbulent mixing due to the existence of a surface. Also, negative peaks at the center of the turbine rotor were observed because there were few radially diffused wakes. In the post-turbine area, the ejection motion was decreased and the sweep motion was increased, showing that wake recovery induced by high speed velocity at the top of the wind farm occurs.

To be used in the parameterization for regional-scale simulations (Eqs. 15-18), the power coefficient and thrust coefficient of the wind farm were calculated for each turbine. Each row average of these coefficients for the 64 turbines is plotted in Figure 9. With a wind speed of $8 \mathrm{~m}$ $\mathrm{s}^{-1}$ at the hub height, the total averages of the thrust and power coefficients were 0.659 and 0.158 , respectively, which are lower than the coefficients provided by the turbine manufacturer (the coefficients at $1^{\text {st }}$ row). Compared to the coefficients at the $1^{\text {st }}$ row, the total average of the thrust 
and the power coefficients were decreased by $27 \%$ and $48 \%$, respectively. This indicates that interactions between turbines decrease power generation, whereas the thrust coefficient was less affected by these interactions.

\subsection{Impact of the wind farm on the neutral boundary layer}

Through a regional-scale simulation of the NBL dynamics with wind farm parameterization, the effects of the wind farm on the NBL were analyzed. Four simulation cases were constructed to evaluate different coefficients obtained from the WindBlade results. (Case_1: no wind farm, Case_2: coefficients only at first row, Case_3: averaged coefficients at each turbine, Case_4: different coefficients for the rows). Wind farm parameterization was applied to a $3 \mathrm{~km} \times 3 \mathrm{~km} \mathrm{x}$ $0.16 \mathrm{~km}$ region at the center of the entire domain. Figure 10 shows that the simulations approached a quasi-steady state based on the convergence of the averaged friction velocity across the wind farm area for cases with and without wind farm parameterization. Simulations with and without wind farm parameterization had similar developing periods and convergence rates. When the time normalized by the large eddy turn-over time $\left(\mathrm{t}^{*}=\mathrm{H} / \mathrm{u} \sim 833 \mathrm{~s}\right)$ is below 30 , friction velocities are still under development. After $30 \mathrm{t} / \mathrm{t}^{*}$, the flow approached a quasi-steady state, having different magnitudes of $0.432 \mathrm{~m} \mathrm{~s}^{-1}, 0.407 \mathrm{~m} \mathrm{~s}^{-1}, 0.413 \mathrm{~m} \mathrm{~s}^{-1}$ and $0.414 \mathrm{~m} \mathrm{~s}^{-1}$, respectively for Case_1 through Case_4. Although each case had a different magnitude due to a different KE deficit of the wind farm, friction velocities for all cases converged. To analyze the time-averaged result, we obtained the velocity field every three minutes between $56.9 \sim 60.5 \mathrm{t} / \mathrm{t}^{*}$ (physical time: $13 \sim 14$ hours).

For the validation of NBL simulation using the WRF model, the normalized velocity and logarithmic line versus the height normalized by the boundary layer depth are shown in Figure 11. It is observed that initial geostrophic wind adjusts near the surface and inversion layer. It was shown that the normalized velocity near the surface had similar tendencies with the theoretical line obtained from the logarithmic law of the wall. This suggested that the WRF simulation with 100 vertical grids was sufficient to reproduce the structure of the boundary layer.

To observe the velocity deficit distribution induced by the wind farm, contours of the streamwise velocity difference between cases with and without a wind farm are shown in Figure 12-(a). 
It was observed that the effect of the wind farm was mainly diffused in the stream-wise direction and reached the end of the domain (about $9 \mathrm{~km}$ ). The velocity deficit in Case_3 and Case_4 had similar features, indicating that the effect of the local distribution of the coefficients with row was not significant. The velocity in Case_2 decreased to about $2.8 \mathrm{~m} \mathrm{~s}^{-1}$ in the wind farm area, while velocities in Case_3 and Case_4 decreased to about $2.4 \mathrm{~m} \mathrm{~s}^{-1}$. This means that the case with coefficients at the first row of the wind farm overestimated the velocity deficit by about $14 \%$ compared to the coefficients that considered the wind farm effect. Also, the high speed streak in the lateral sides of the wind farm was formed due to the existence of the wind farm,

showing that the difference in the magnitude of the stream-wise velocity is about $-0.4 \mathrm{~m} \mathrm{~s}^{-1}$. Small oscillations are present in the $y$-direction, most likely attributed to slight transversal displacement of the wind farm wake with time. In Figure 12-(b), a change in the boundary layer is observed in the $x z$-plane contour. In the wind farm region, a strong velocity deficit inside the wind farm and a high-speed velocity over the wind farm occurred simultaneously. Behind the wind farm region, the wake and velocity deficit were diffused in both the stream-wise and the vertical direction. However, there was no significant change in terms of the boundary layer depth.

To quantitatively compare the KE deficit and TKE gain in the vertical direction, vertical profiles of the difference (comparison was between with and without a wind farm) in the stream-wise velocity and SGS TKE averaged in the dot-box in Figure 12 are plotted in Figure 13. Strong velocity deficit and generation of TKE occurred below $200 \mathrm{~m}$ and small KE and TKE were diffused up to $200 \mathrm{~m}$. However, based on the boundary layer depth calculation (mean stress was $5 \%$ of the surface value calculated by the square of the friction velocity), the boundary layer depth in Case_1 was about $308 \mathrm{~m}$ and the boundary layer depth in Case_2, 3, and 4 was about $319 \mathrm{~m}$ [Kosovic and Curry, 2000]. This means that the diffused wake from the wind farm slightly increased the boundary layer depth.

\section{CONCLUSIONS}

Flow in a wind farm was simulated using the WindBlade model to capture turbine-to-turbine interactions. A regional-scale WRF simulation was also performed to assess the impact of the 
thrust and power coefficients on a regional-scale wind farm parameterization using improved coefficients derived from the high-resolution WindBlade simulation. In the WindBlade wind farm simulation, the three-dimensional velocity deficit and the interactions between turbines caused by insufficient distance between turbine rows were observed, including significant changes in the vertical distributions of momentum and turbulent intensity due to the turbineinduced mixing. Tip and shear vortices were observed in the wake of the wind turbines. Furthermore, the wake had directional characteristics, confirmed by vertical variation in the turbulent intensity. Quadrant analysis was used to evaluate the direction of turbulent mixing and revealed that the amount of ejection motion induced is large compared to other types of quadrant motions. This effect was caused by the presence of the turbine, indicating that the sweep motion was increased at the location where a strong wake recovery occurred. In regional-scale NBL simulation, the velocity deficit and SGS TKE caused by parameterized wind turbines slightly increased the boundary layer depth locally. In terms of the velocity deficit and SGS TKE, the effect of considering the local distribution of coefficients with row was not significant. However, simulations with wind farm parameterizations that only contained the first row coefficients and averaged coefficients exhibited about 5\% variation in SGS TKE, although no noticeable change in boundary layer depth was observed. Despite the fact that the wind farm caused relatively few changes in the boundary layer height in the NBL (compared to previous SBL studies by Lu and Porte, and Park et al.), turbine coefficients that consider interference in the wind farm must be used in wind farm parameterization in order to more accurately investigate the various wind farm effects on the atmospheric boundary layer.

\section{ACKNOWLEDGMENTS}

This work was supported by a grant from the Midcareer Researcher Program of the National

Research Foundation of Korea (NRF), funded by the Ministry of Science, ICT, and Future Planning (grant NRF-2013R1A2A2A01015333). This work was also supported by the National Research Foundation of Korea (NRF) Grant funded by the Korean Government (MSIP) (No. 2015R1A5A1037668). WindBlade is developed with the support by Los Alamos National Laboratory's (LANL) Laboratory Directed Research and Development (LDRD) program (20100040DR), and LANL Institutional Computing (IC) provided high-performance computing 
resources under w12_windturbines project. The fourth author is supported by Korea Institute of Atmospheric Predictions Systems funded by the Korea Meteorological Administration.

\section{REFERENCES}

[1] Petersen EL, Mortensen NG, Landberg L, Højstrup J, Frank HP. Wind power meteorology. Part I: climate and turbulence. Wind Energy 1998;1.s 1:25-45.

[2] Vermeer, LJ, Sørensen JN, Crespo A. Wind turbine wake aerodynamics. Prog. Aerosp. Sci. 2003;39(6):467-510.

[3] Roy SB., Pacala SW, Walko RL. Can large wind farms affect local meteorology. J. Geophys. Res.:Atmos (1984-2012) 2004;109.D19101.

[4] Kirk-Davidoff DB, Keith DW. On the climate impact of surface roughness anomalies. J. Atmos. Sci. 2008;65(7):2215-2234.

[5] Keith DW, DeCarolis JF, Denkenberger DC, Lenschow DH, Malyshev SL, Pacala S, Rasch PJ. The influence of large-scale wind power on global climate. Proc. Natl. Acad. Sci. U.S.A. 2004;101(46):16115-16120.

[6] Wang C, Prinn RG. Potential climatic impacts and reliability of very large-scale wind farms. Atmos. Chem. Phys. 2010;10(4):2053-2061.

[7] Wang C, Prinn RG. Potential climatic impacts and reliability of large-scale offshore wind farms. Environ. Res. Lett. 2011;6(2):025101.

[8] Fitch AC, Olson JB, Lundquist JK. Parameterization of wind farms in climate models. J. Clim. 2013;26(17):6439-6458.

[9] Adams AS, Keith DW. Wind energy and climate: Modeling the atmospheric impacts of wind energy turbines. AGU Fall Meeting Abstracts 2007;1:p. 08.

[10] Roy SB, Traiteur JJ. Impacts of wind farms on surface air temperatures. Proc. Natl. Acad. Sci. U.S.A. 2010;107(42):17899-17904.

[11] Fitch AC, Olson JB, Lundquist JK., Dudhia J, Gupta AK, Michalakes J, Barstad I. Local and mesoscale impacts of wind farms as parameterized in a mesoscale NWP model. Mon. Weather. Rev. 2012;140(9):3017-3038.

[12] Stull RB. An introduction to boundary layer meteorology. Springer Science \& Business Media; 1988. 
[13] Moeng CH, Sullivan PP. A comparison of shear-and buoyancy-driven planetary boundary layer flows. J. Atmos. Sci. 1994;51(7):999-1022.

[14] Na JS, Jin EK, Lee JS. Investigation of Kelvin- Helmholtz Instability in the stable boundary layer using large eddy simulation. J. Geophys. Res.:Atmos 2014;119(13):78767888

[15] Porté-Agel F, Wu YT, Lu H, Conzemius RJ. Large-eddy simulation of atmospheric boundary layer flow through wind turbines and wind farms. J. Wind Eng. Ind. Aerodyn. 2011;99(4):154-168.

[16] Lu H, Porté-Agel F. Large-eddy simulation of a very large wind farm in a stable atmospheric boundary layer. Phys. Fluids (1994-present) 2011;23(6):065101.

[17] Park J, Basu S, Manuel L. Large-eddy simulation of stable boundary layer turbulence and estimation of associated wind turbine loads. Wind Energy 2014;17(3):359-384.

[18] Porté-Agel F, Lu H, Wu YT. Interaction between large wind farms and the atmospheric boundary layer. Procedia IUTAM 2014;10:307-318.

[19] Zhang W, Markfort CD, Porté-Agel F. Wind-turbine wakes in a convective boundary layer: A wind-tunnel study. Boundary-layer Meteorol. 2013;146(2):161-179.

[20] Linn RR, Koo E. Determining effects of turbine blades on fluid motion (Patent 7,953,563). Los Alamos National Laboratory (LANL), Los Alamos, NM (United States), 2011.

[21] Linn RR, Koo E. Determining effects of turbine blades on fluid motion ( Patent 8,170,813). Los Alamos National Laboratory (LANL), Los Alamos, NM (United States), 2012.

[22] Linn RR. A transport model for prediction of wildfire behavior, (Sci. Rep LA-13334-T). Los Alamos National Lab., NM (United States), 1997.

[23] Pimont F, Dupuy JL., Linn RR, Dupont S. Validation of FIRETEC wind-flows over a canopy and a fuel-break. Int. J. Wildland Fire. 2009;18(7):775-790.

[24] Cunningham P, Linn RR, Koo E, Wilson CJ. Large-eddy simulations of air flow and turbulence within and around low-aspect-ratio cylindrical open-top chambers. J. Appl. Meteorol. Climatol. 2013;52(8):1716-1737. 
[25] Smolarkiewicz PK, Margolin LG. MPDATA: A finite-difference solver for geophysical flows. J. Comput. Phys. 1998;140(2):459-480.

[26] Reisner J, Wynne S, Margolin L, Linn R. Coupled atmospheric-fire modeling employing the method of averages. Mon. Weather. Rev. 2000;128(10):3683-3691.

[27] Butterfield S, Musial W, Scott G. Definition of a 5-MW reference wind turbine for offshore system development. Golden, CO: National Renewable Energy Laboratory, 2009.

[28] Frandsen S, Barthelmie R, Pryor S, Rathmann O, Larsen S, Højstrup J, Thøgersen M. Analytical modelling of wind speed deficit in large offshore wind farms. Wind energy 2006;9(1-2):39-53.

[29] Nakanish M. Improvement of the Mellor-Yamada turbulence closure model based on large-eddy simulation data. Boundary-layer Meteorol. 2001;99(3):349-378.

[30] Mirocha J, Kosovic B, Kirkil G, Resolved turbulence characteristics in large-eddy simulations nested within mesoscale simulations using the Weather Research and Forecasting Model. Mon. Weather. Rev. 2014;142:806-831.

[31] Muñoz-Esparza D, Kosovic B, Mirocha J, Beeck J, Bridging the transition from mesoscale to microscale turbulence in numerical weather prediction models. Boundary-layer Meteorol. 2014;153:409-440.

[32] Muñoz-Esparza D, Kosovic B, Beeck J, Mirocha J, A stochastic perturbation method to generate inflow turbulence in large-eddy simulation models: Application to neutrally stratified atmospheric boundary layers, Phys. Fluids (1994-present) 2015;27(3):035102.

[33] Linn R, Koo E, Kelley ND, Jonkman B, Lundquist JK, Canfield J. Using Dynamically coupled turbine/wind simulations to investigate the influence of atmospheric turbulence in turbine wake recovery. AGU Fall Meeting Abstracts 2010;1: p. 03.

[34] Koo E, Linn R, Bossert JA, Kelley ND, Lundquist JK. Using dynamically coupled turbine/wind simulations to investigate the influence of atmospheric turbulence in turbine wake recovery. AGU Fall Meeting Abstracts 2011;1: p. 0867.

[35] Kosovic, B; Curry, JA. A large eddy simulation study of a quasi-steady, stably stratified atmospheric boundary layer. J. Atmos. Sci., 2000, 57.8: 1052-1068. 
(a) Wind farm (64 turbines) simulation using HIGRAD/Windblade model $<$ Boundary condition $>$ $<$ Computational domain $>$

\begin{tabular}{|l|}
\hline $\begin{array}{l}\text { Inlet : Dirichlet } \\
\text { condition with } 1 / 7^{\text {th }} \\
\text { law vertical profile } \\
\text { ( Uat hub }=8 \mathrm{~m} / \mathrm{s} \text { ) }\end{array}$ \\
\hline Outlet : Extrapolation \\
\hline $\begin{array}{l}\text { Lateral : Periodic } \\
\text { (Cyclic) Boundary }\end{array}$ \\
\hline Surface : No-slip \\
\hline Top : Free-Shear \\
\hline
\end{tabular}

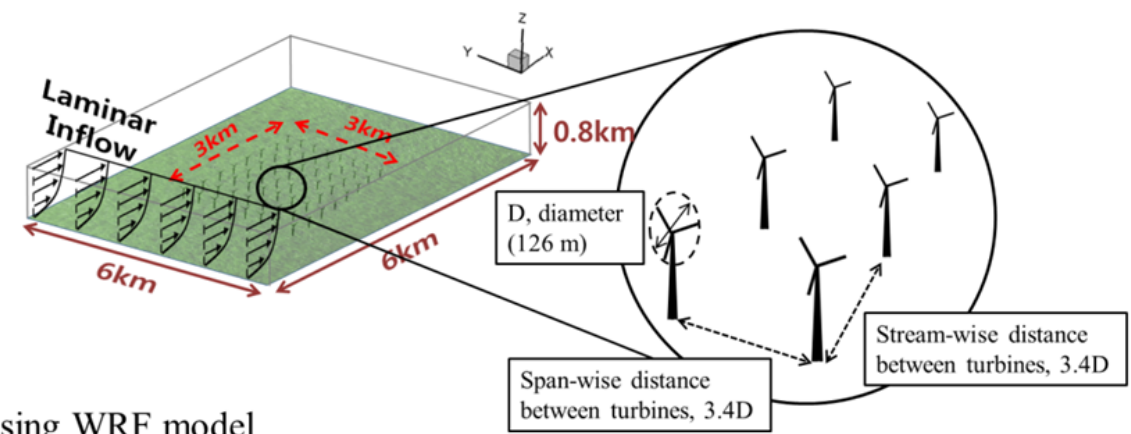

(b) Meso-scale simulation using WRF model

\begin{tabular}{|l|}
\hline $\begin{array}{l}\text { Input sounding : Geostrophic } \\
\text { wind }-10 \mathrm{~m} / \mathrm{s}, \mathrm{z}=500 \mathrm{~m}- \\
\text { inversion layer }\end{array}$ \\
\hline $\begin{array}{l}\mathrm{x}, \mathrm{y} \text { direction boundary : } \\
\text { Domain } 1: \text { Periodic Boundary } \\
\text { condition } \\
\text { Domain } 2 \text { : Domain } 1 \text { result } \\
\text { (one-way nesting) }\end{array}$ \\
\hline Surface : No-slip \\
\hline Top : Free-Shear \\
\hline $\begin{array}{l}\text { Parameterization : Only } \\
\text { boundary layer physics } \\
\text { (MYNN-2.5) }\end{array}$ \\
\hline
\end{tabular}

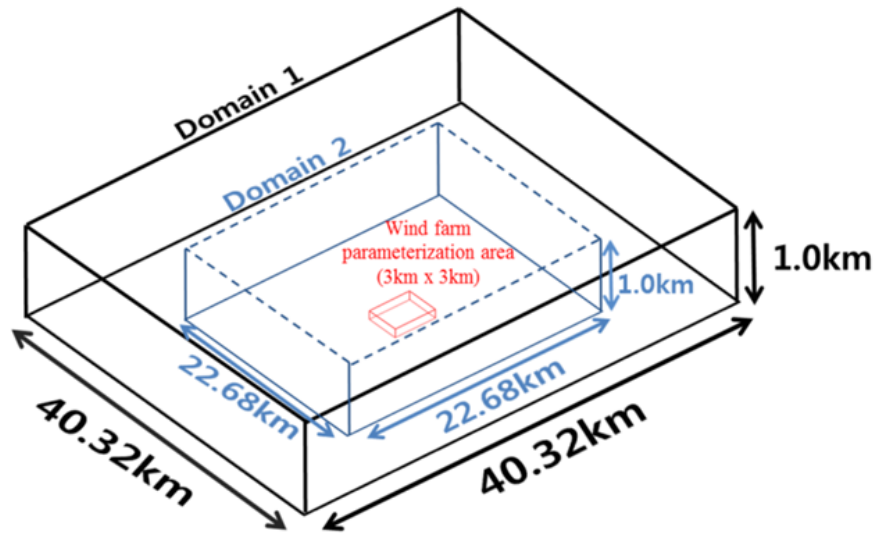

Figure 1: Boundary conditions and computational domains for simulation. (a) Wind farm simulation using the HIGRAD/WindBlade model and (b) a regional-scale simulation using WRF to determine the impact of the wind farm in the NBL. 
(a)

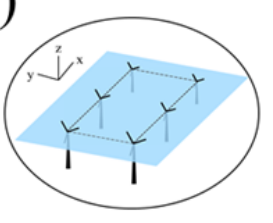

(b)

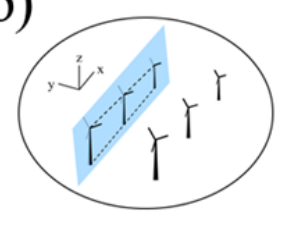

$<$ xy-plane at hub height $>$

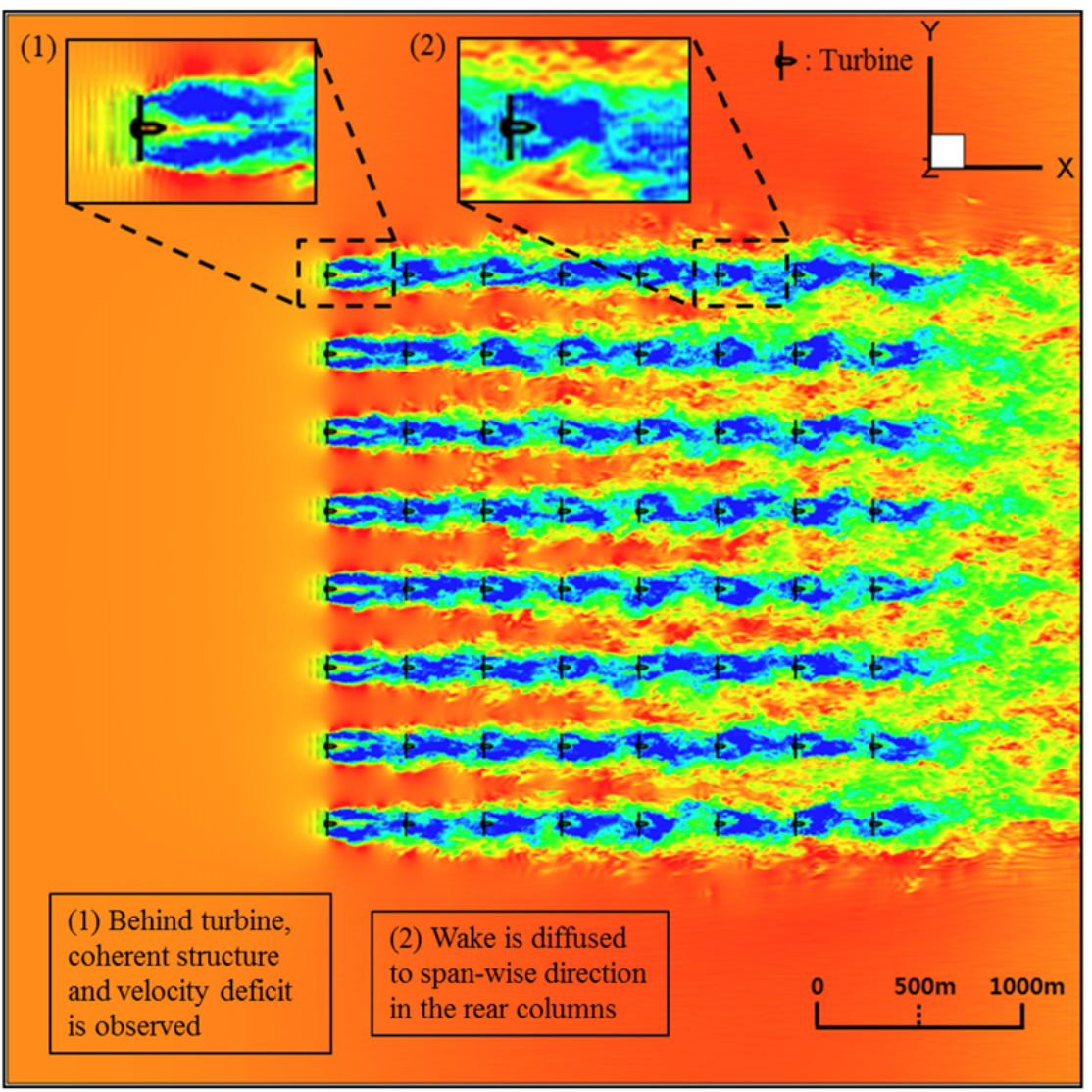

$<\mathrm{x}-\mathrm{z}$ cross-section plane at the center of $5^{\text {th }}$ row of wind farm $>$
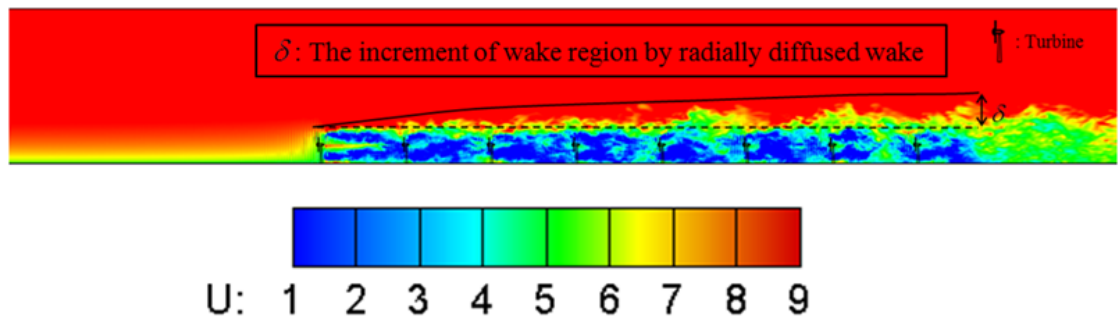

$\left(m s^{-1}\right)$

Figure 2: Instantaneous ( $800 \mathrm{~s}$ ) contour of stream-wise velocity from the HIGRAD/WindBlade model. (a) On the $x-y$ plane ( $z=90 \mathrm{~m}$, hub height) and (b) on the $x-z$ plane cutting through the center of the $5^{\text {th }}$ column of turbines on the wind farm. 
(a) Stream-wise velocity

: Area swept by blade

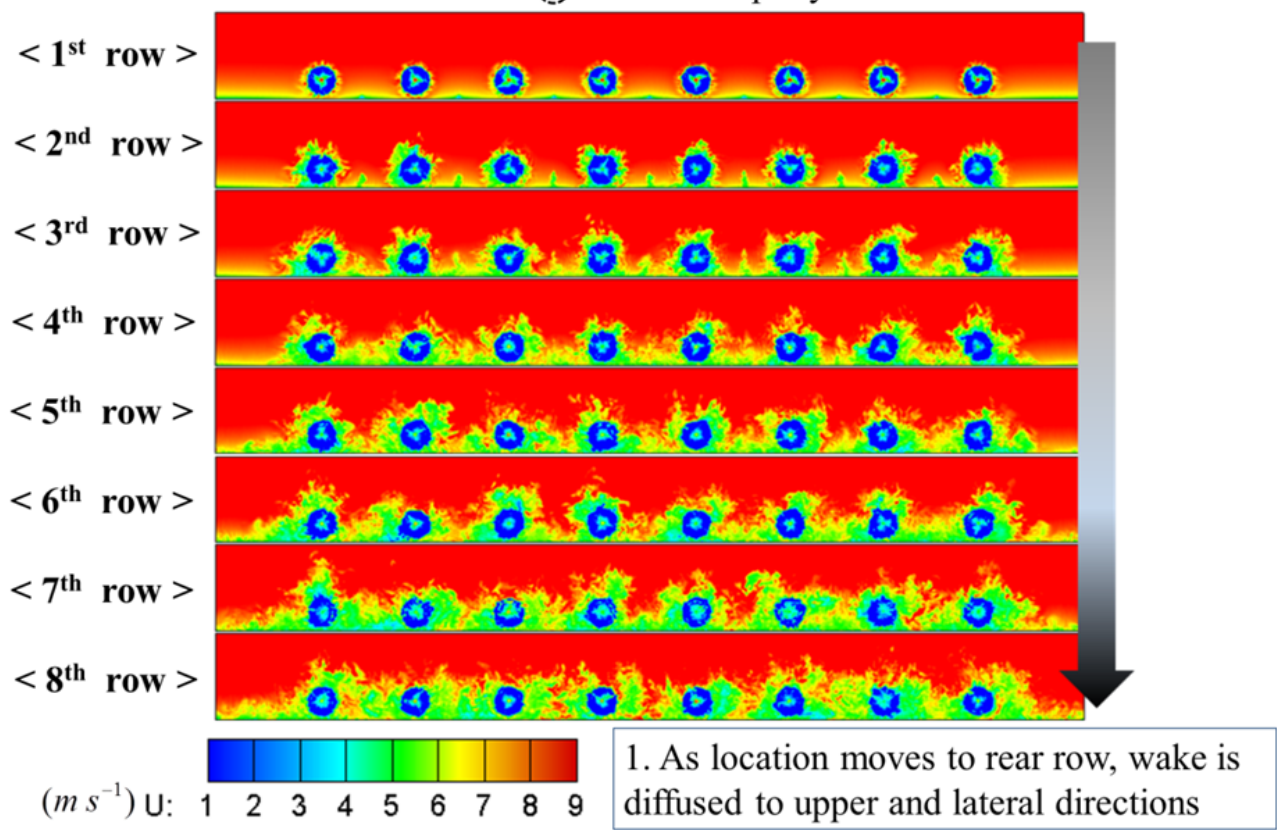

(b) Shear gradient $(d U / d z) \quad$ : Area swept by blade

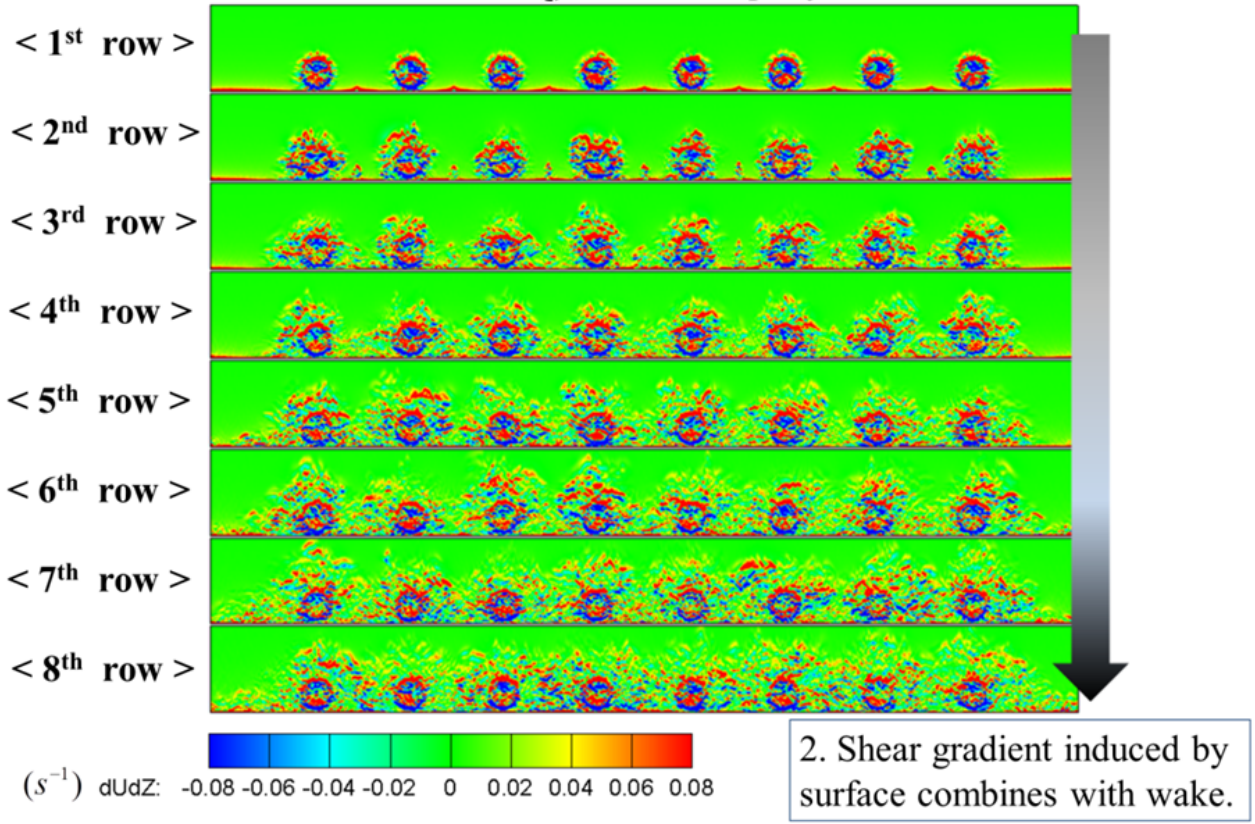

Figure 3: Contours of the instantaneous stream-wise velocity and shear gradient in the individual rows of the wind farm showing the diffused wake near the rotor area. (a) Stream-wise velocity and (b) shear gradient (dU/dz). 


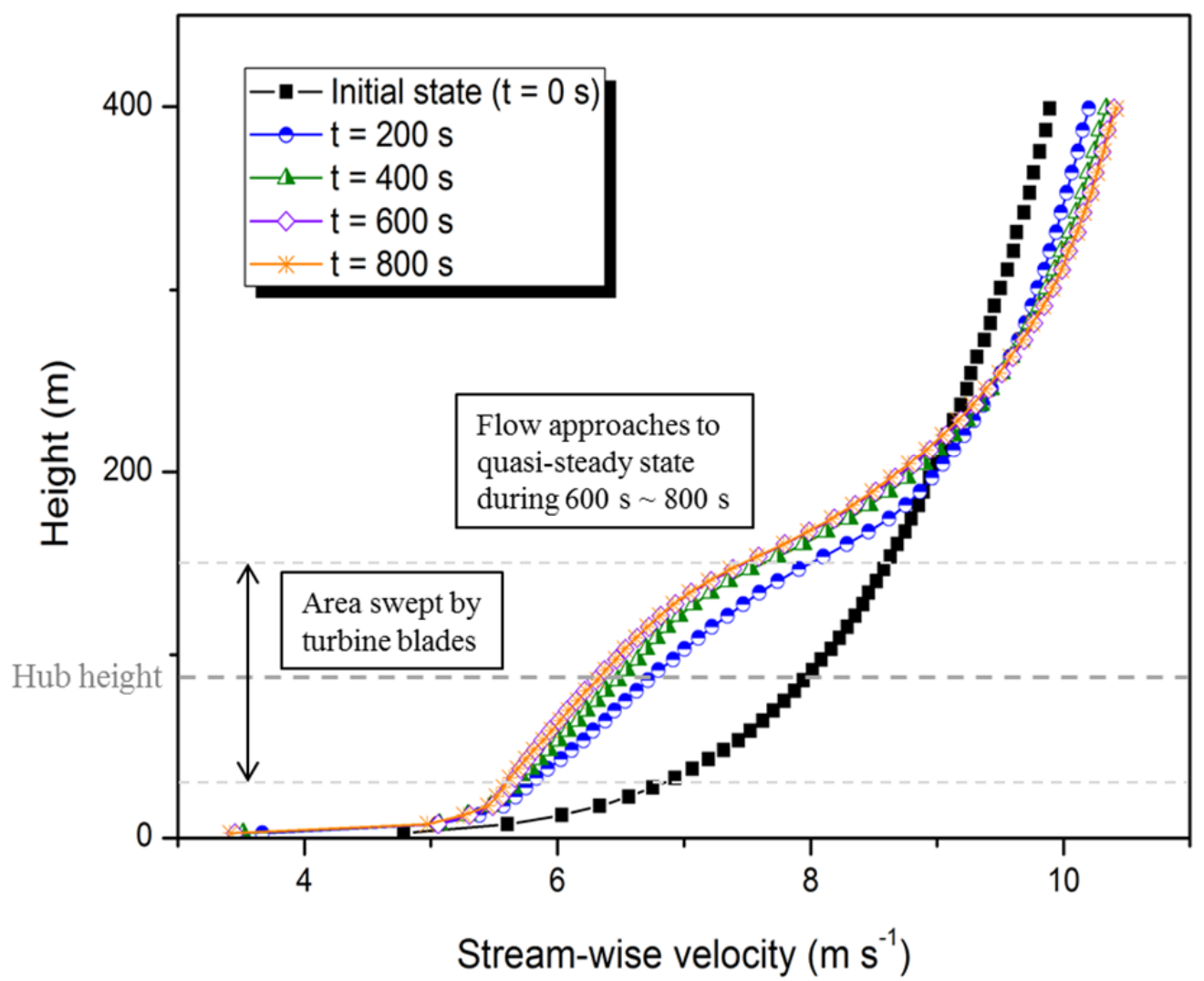

Figure 4: Time-evolution of vertical profiles of stream-wise velocity averaged horizontally in the wind farm area, showing a remarkable velocity deficit and quasi-steady state of flow during developing time (0 s $\sim 800 \mathrm{~s})$. 
(a)
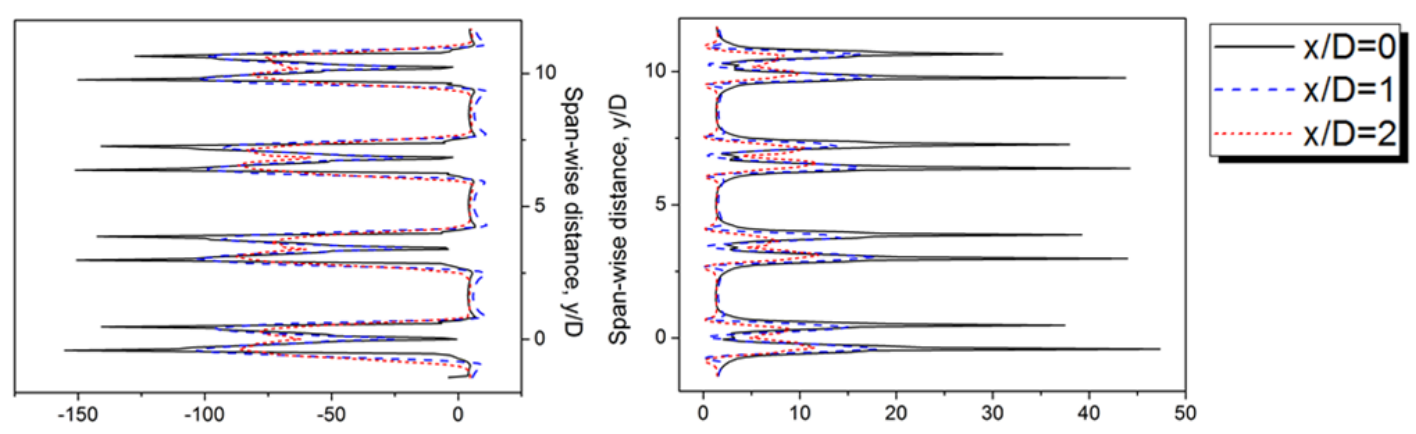

(b) $3^{\text {rd }}$
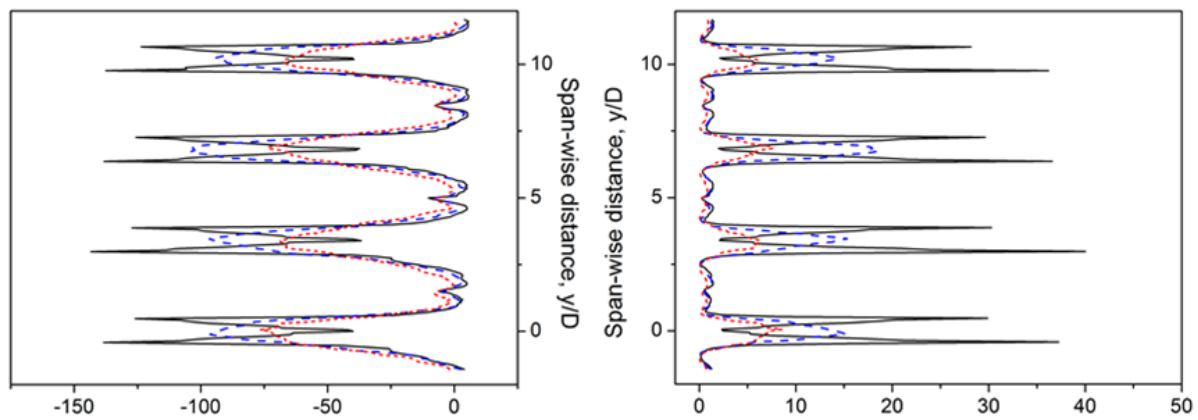

(c) $5^{\text {th }}$
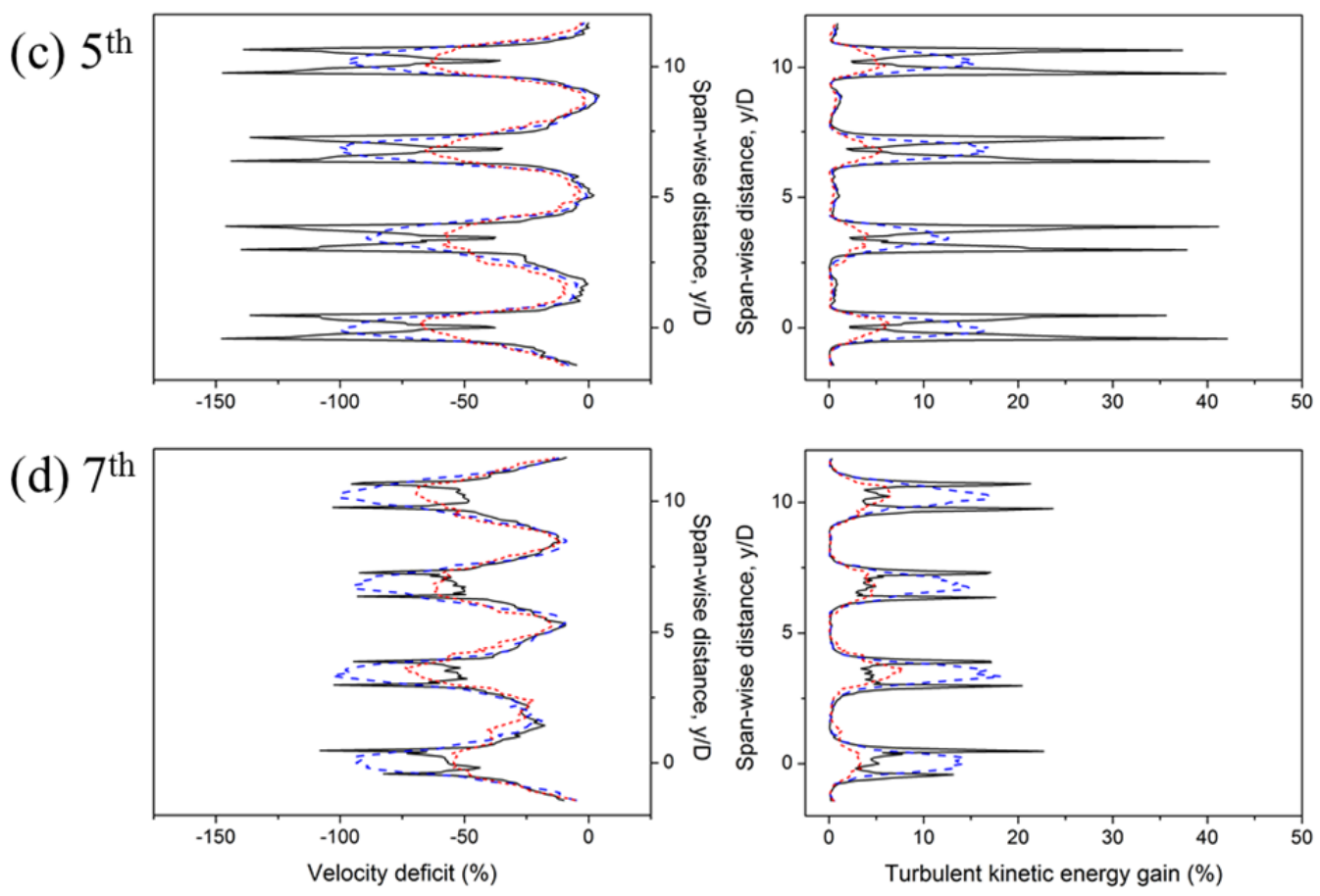

velocity deficit $=\left(u-u_{\infty}\right) / u_{\infty} \times 100(\%)$

Turbulent kinetic energy gain

$$
=\left(u^{\prime 2}+v^{\prime 2}+w^{\prime 2}\right) / 2 u_{\infty}^{2} \times 100(\%)
$$

Figure 5: Wake statistics for every row of the wind farm to show the diffused wake near the rotor area. Left panel and right panel show the velocity deficit and TKE gain, respectively. (a)

$$
1^{\text {st }} \text {, (b) } 3^{\text {rd }} \text {, (c) } 5^{\text {th }} \text {, (d) } 7^{\text {th }} \text { rows. }
$$


(a) $\mathrm{t}=30 \mathrm{~s}$ (initial state)

(b) $\mathrm{t}=100 \mathrm{~s}$ (developing state)

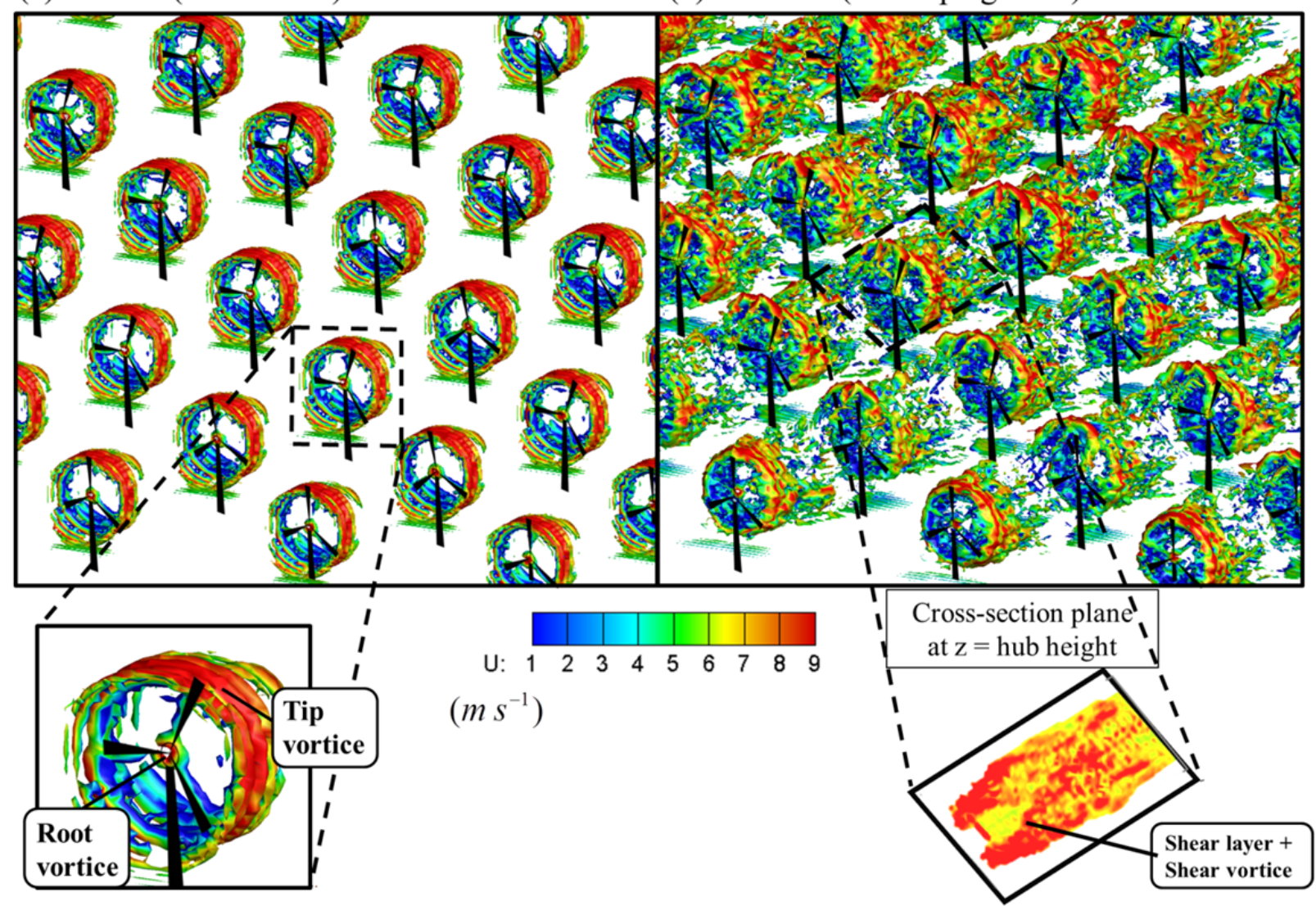

Figure 6: Iso-surface of the vorticity magnitude colored by the stream-wise velocity at instantaneous fields for $\mathrm{t}=30 \mathrm{~s}$ (near initial state) and $100 \mathrm{~s}$ (in the developing state). (a) $\mathrm{t}=30 \mathrm{~s}$, vorticity magnitude $|\omega|$ is the same as $\frac{1}{5}\left|\omega_{\max }\right|$ and $(\mathrm{b}) \mathrm{t}=100 \mathrm{~s}$, vorticity magnitude $|\omega|$ is the same as $\frac{1}{5}\left|\omega_{\max }\right|$. 


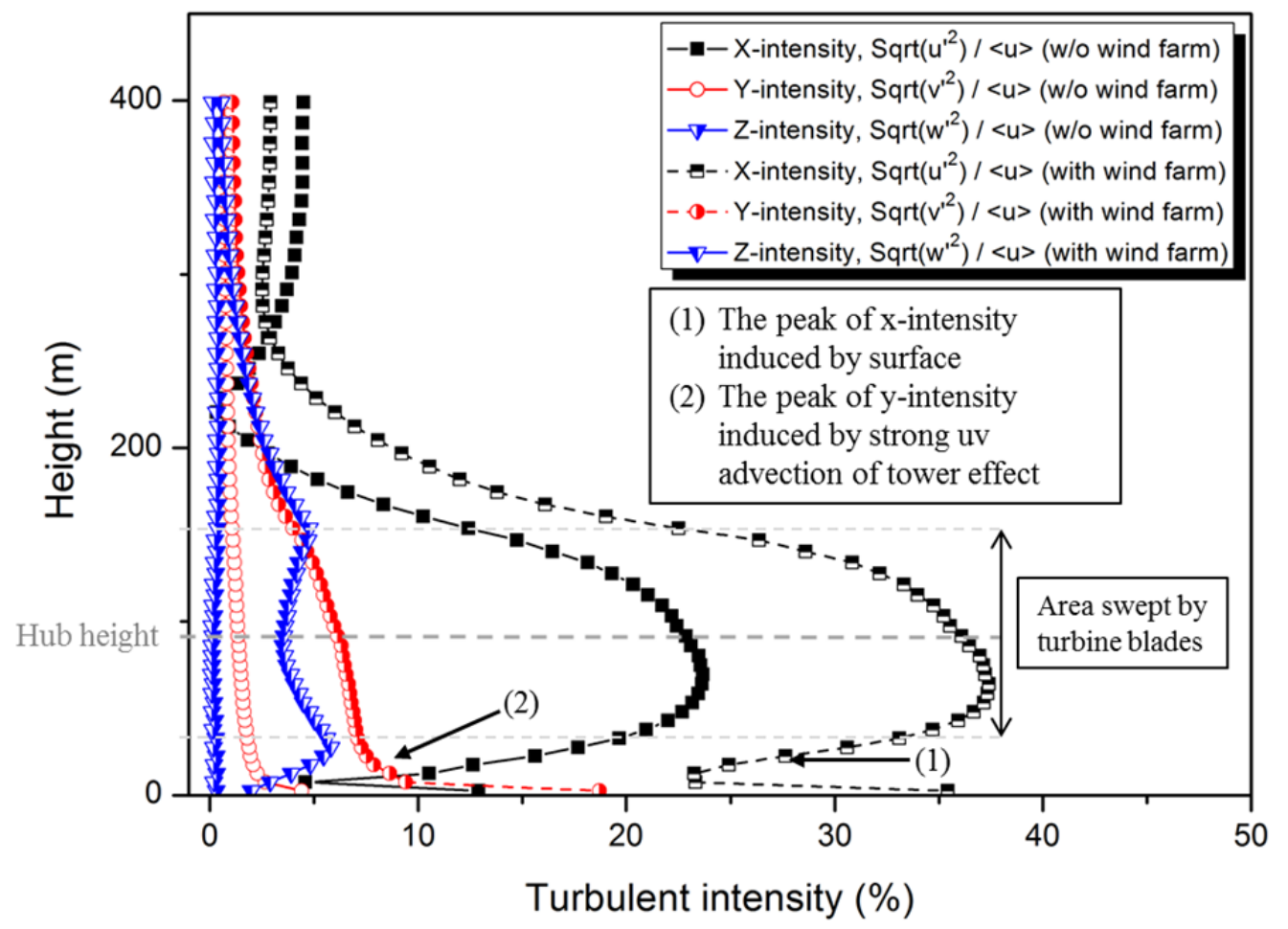

Figure 7: Vertical profile of the turbulent intensity (\%) calculated as the root mean square of the velocity over the mean velocity $<\mathrm{u}>$. 


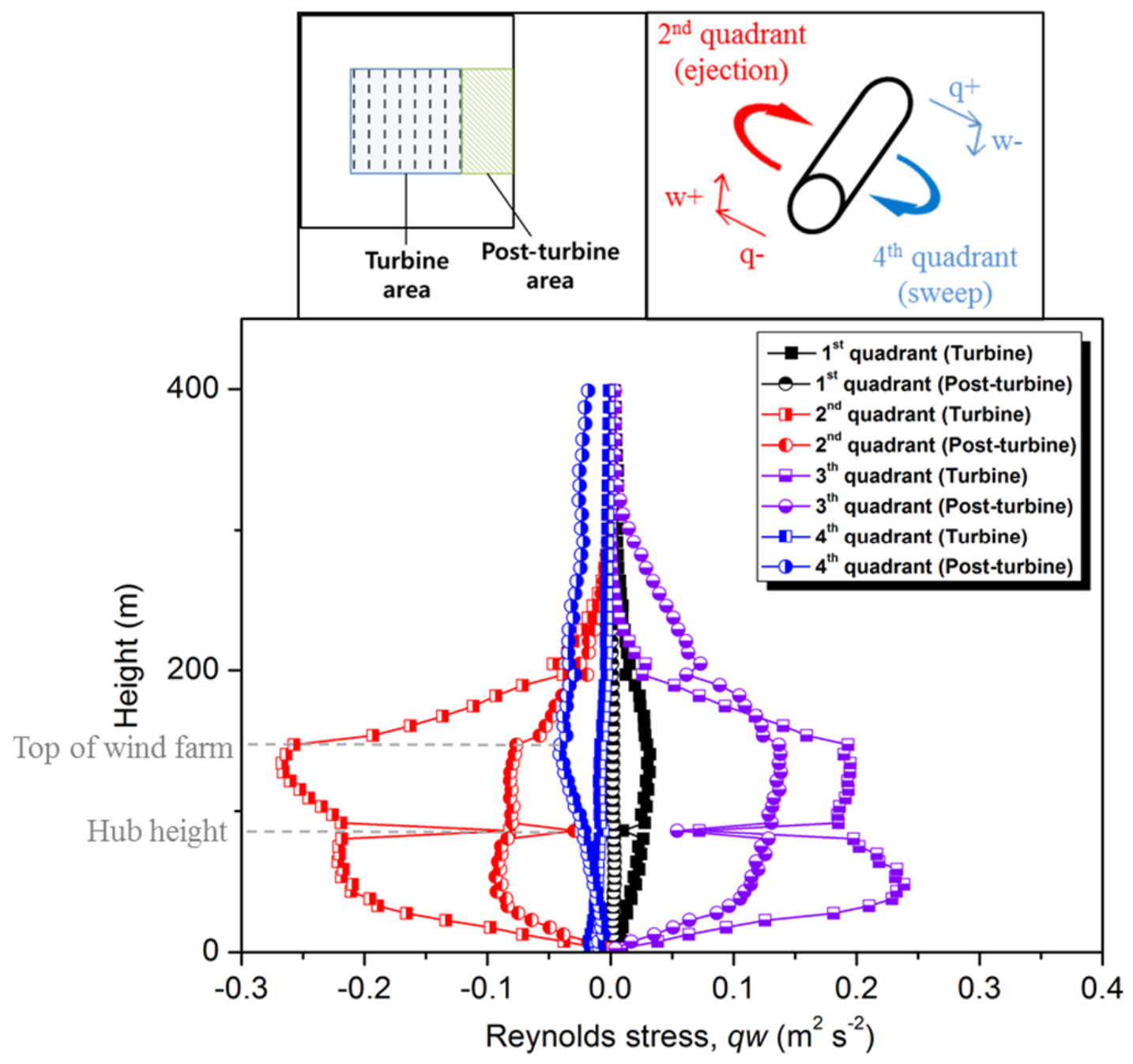

Figure 8: Vertical profiles of quadrant components of the $q w$ Reynolds stress showing coherent mixing due to the interaction between the horizontal and vertical velocity fluctuations. The $2^{\text {nd }}$ and $4^{\text {th }}$ quadrants denote the ejection corresponding to upward mixing, while the sweep corresponds to downward mixing. 


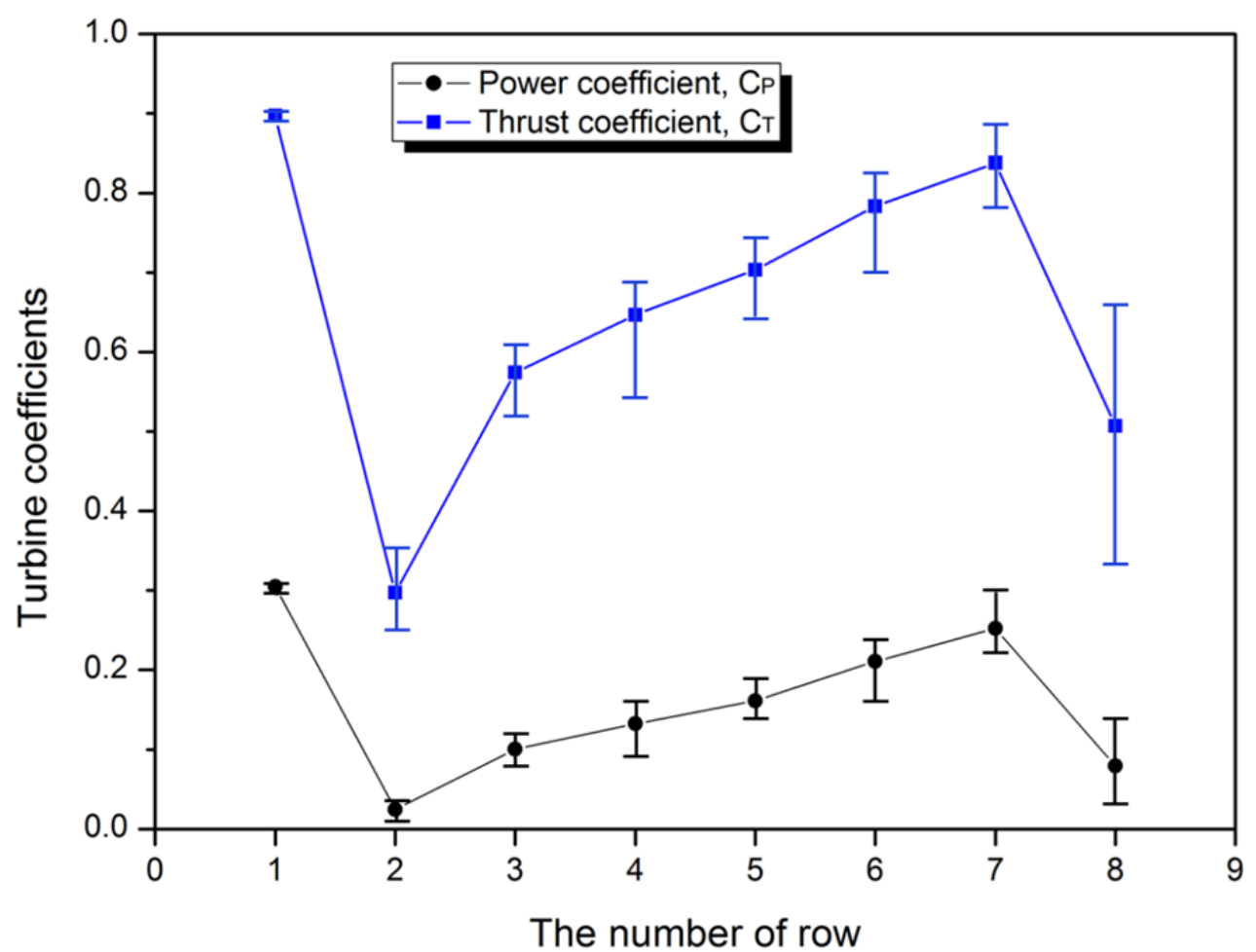

Figure 9: The thrust coefficient and the power coefficient variations of the wind turbines at different rows. The solid diagonal line represents the span-wise variability between turbines in the same row. 


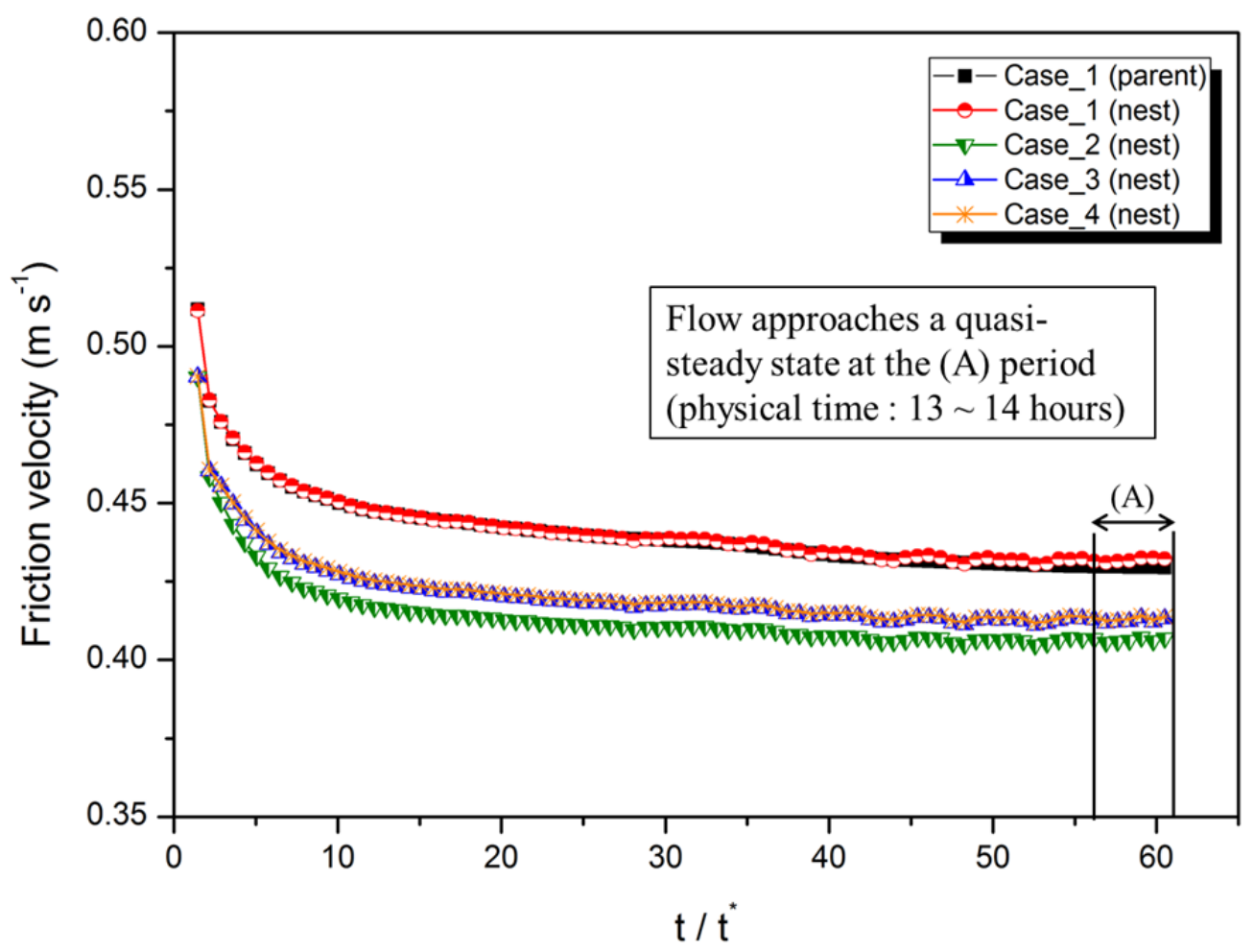

Figure 10: Time series of friction velocity in the simulation with and without wind farm parameterization. 


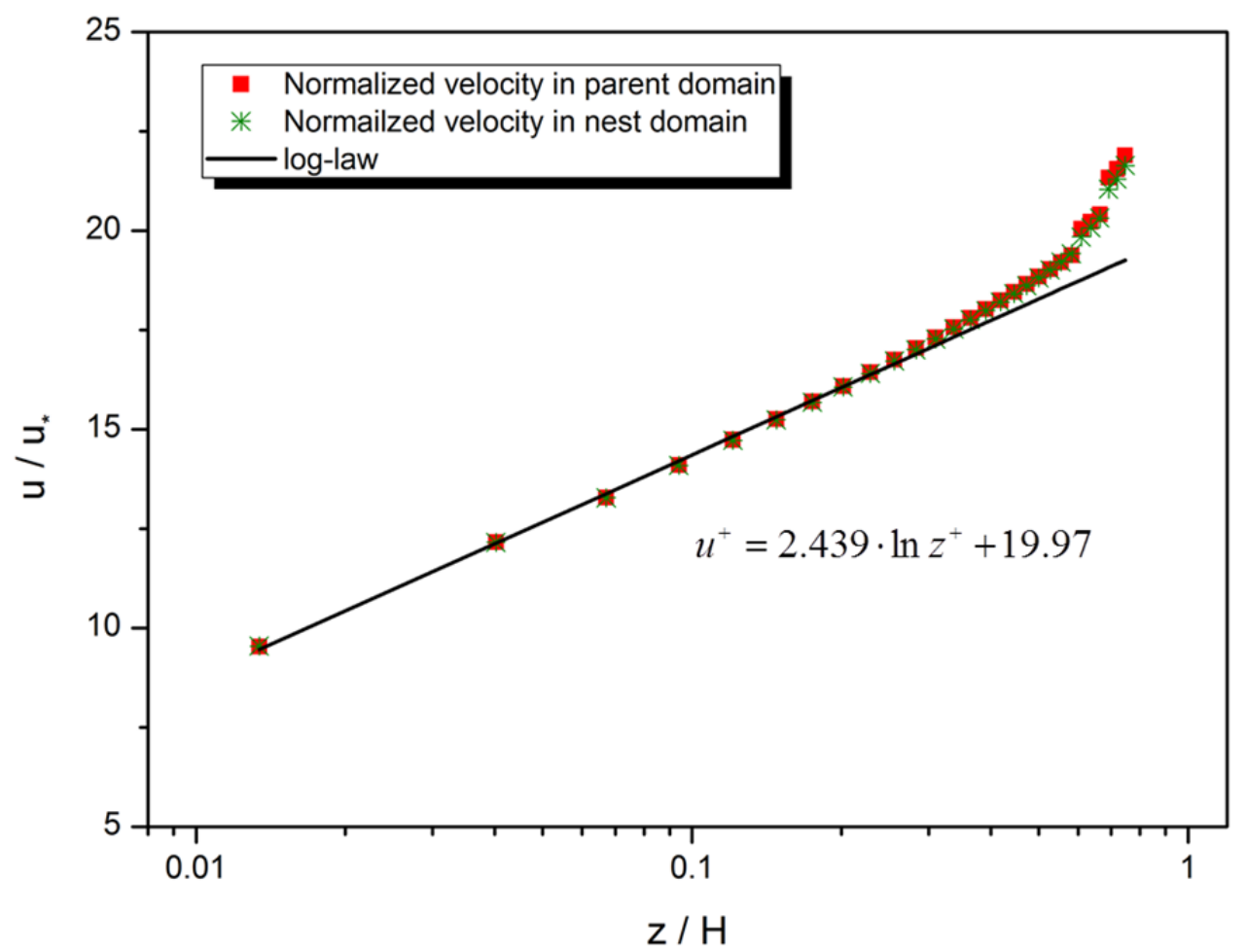

Figure 11 : Normalized velocity versus vertical height normalized by the boundary layer depth

(H) for WRF simulation without the wind farm. Logarithmic line is calculated by

$$
u^{+}=1 / k \ln \left(z^{+}\right)+1 / k \ln \left(H / z_{0}\right) \text {. }
$$


(a) xy-plane

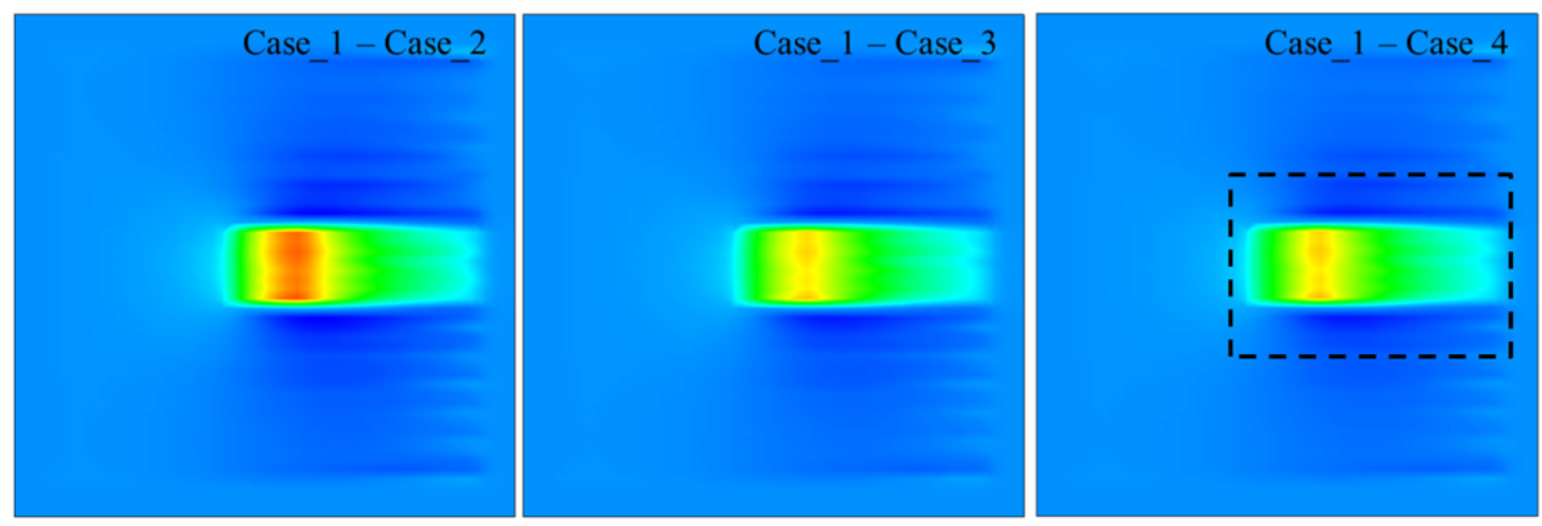

(b) xz-plane

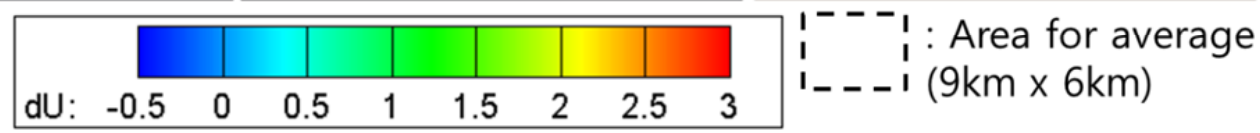

\section{Case_1 - Case_2}

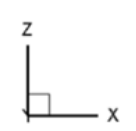

\section{Case_1 - Case_3}

\section{Case_1 - Case_4}

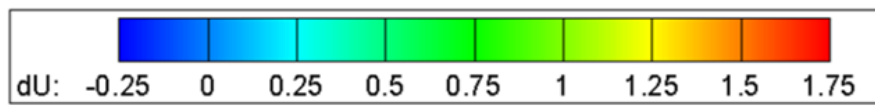

Figure 12 : Contours of difference between Case_1 and Case_2, 3 and 4. (a) Time averaged stream-wise velocity in the $x y$-plane (at the hub height, $90 \mathrm{~m}$ ) and (b) time averaged stream-wise velocity in the $x z$-plane. (at the center of domain) 

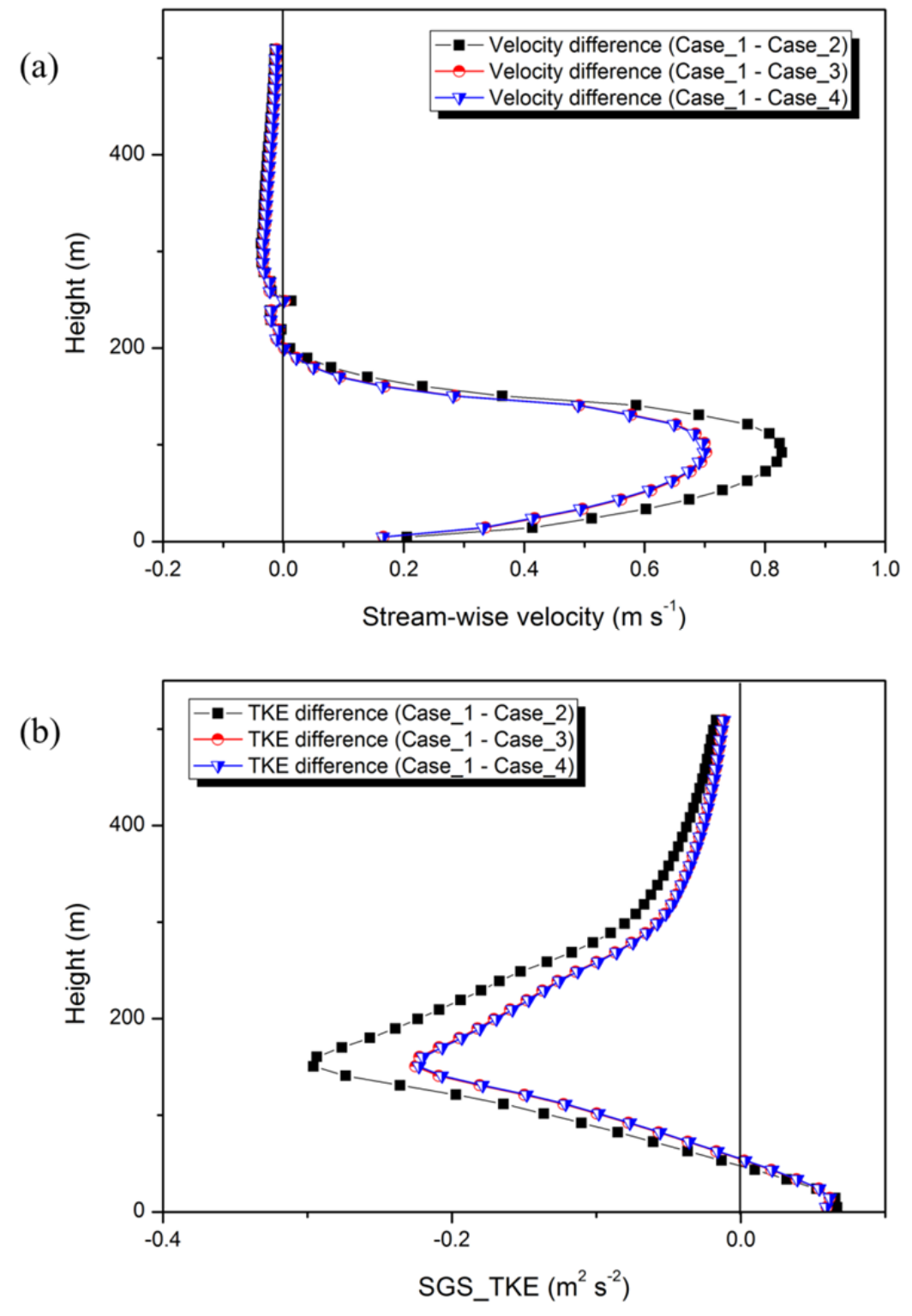

Figure 13: Vertical profiles of difference between Case_1 and Case_2, 3 and 4. (a) Stream-wise velocity averaged in the previous dot-box and (b) SGS TKE averaged in the previous dot-box. 